\title{
Recovery of menses after functional hypothalamic amenorrhoea: if, when and why
}

\author{
Pape, J ; Herbison, A E ; Leeners, B
}

\begin{abstract}
BACKGROUND Prolonged amenorrhoea occurs as a consequence of functional hypothalamic amenorrhoea (FHA) which is most often induced by weight loss, vigorous exercise or emotional stress. Unfortunately, removal of these triggers does not always result in the return of menses. The prevalence and conditions underlying the timing of return of menses vary strongly and some women report amenorrhoea several years after having achieved and maintained normal weight and/or energy balance. A better understanding of these factors would also allow improved counselling in the context of infertility. Although BMI, percentage body fat and hormonal parameters are known to be involved in the initiation of the menstrual cycle, their role in the physiology of return of menses is currently poorly understood. We summarise here the current knowledge on the epidemiology and physiology of return of menses. OBJECTIVE AND RATIONALE The aim of this review was to provide an overview of (i) factors determining the recovery of menses and its timing, (ii) how such factors may exert their physiological effects and (iii) whether there are useful therapeutic options to induce recovery. SEARCH METHODS We searched articles published in English, French or German language containing keywords related to return of menses after FHA published in PubMed between 1966 and February 2020. Manuscripts reporting data on either the epidemiology or the physiology of recovery of menses were included and bibliographies were reviewed for further relevant literature. The Strengthening the Reporting of Observational Studies in Epidemiology (STROBE) criteria served to assess quality of observational studies. OUTCOMES Few studies investigate return of menses and most of them have serious qualitative and methodological limitations. These include (i) the lack of precise definitions for FHA or resumption of menses, (ii) the use of short observation periods with unsatisfactory descriptions and (iii) the inclusion of poorly characterised small study groups. The comparison of studies is further hampered by very inhomogeneous study designs. Consequently, the exact prevalence of resumption of menses after FHA is unknown. Also, the timepoint of return of menses varies strongly and reliable prediction models are lacking. While weight, body fat and energy availability are associated with the return of menses, psychological factors also have a strong impact on the menstrual cycle and on behaviour known to increase the risk of FHA. Drug therapies with metreleptin or naltrexone might represent further opportunities to increase the chances of return of menses, but these require further evaluation.
\end{abstract}

DOI: https://doi.org/10.1093/humupd/dmaa032

Posted at the Zurich Open Repository and Archive, University of Zurich

ZORA URL: https://doi.org/10.5167/uzh-199826

Journal Article

Accepted Version

Originally published at: 
Pape, J; Herbison, A E; Leeners, B (2021). Recovery of menses after functional hypothalamic amenorrhoea: if, when and why. Human reproduction update, 27(1):130-153.

DOI: https://doi.org/10.1093/humupd/dmaa032 


\section{Recovery of menses after functional hypothalamic amenorrhea}

\section{2 - if, when and why}

3 J. Pape ${ }^{1}$, A.E. Herbison ${ }^{2}$, B. Leeners ${ }^{1,3}$

4

5 1) Department of Reproductive Endocrinology, University Hospital Zurich, 8091 Zurich, Switzerland

6 2) Department of Physiology, Development and Neuroscience, University of Cambridge, CB2 3EG United

7 Kingdom

8 3) University of Zurich, 8091 Zurich, Switzerland

9

10

11 Running title: Recovery of menses after amenorrhea

12

13

14

15

16

17

18

19

20

21

22

23

24

25

26

27

Word count: 9750 


\section{TABLE OF CONTENTS}

29 Introduction

30 Methods

$31 \quad$ Methodological details of included studies

32 Results

Definition and diagnosis of functional hypothalamic amenorrhea (FHA)

Diagnostic criteria for resumption of menses

Causes of FHA and return of menses

Potential mechanisms underlying the return of menses

Discussion

39

Conclusion

40

41

42

43

44

45

46

47

48

49 
BACKGROUND: Prolonged amenorrhea occurs as a consequence of functional hypothalamic amenorrhea (FHA) which is most often induced by weight loss, vigorous exercise or emotional stress. Unfortunately, removal of these triggers does not always result in the return of menses. The prevalence and conditions underlying the timing of return of menses vary strongly and some women report amenorrhea several years after having achieved and maintained normal weight and/or energy balance. A better understanding of these factors would also allow improved counselling in the context of infertility. Although body mass index (BMI), percentage body fat, and hormonal parameters are known to be involved in the initiation of the menstrual cycle, their role in the physiology of return of menses is currently poorly understood. We summarize here current knowledge on the epidemiology and physiology of return of menses.

OBJECTIVE AND RATIONALE: To provide an overview of (i) factors determining the recovery of menses and its timing, (ii) how such factors may exert their physiological effects, and (iii) whether there are useful therapeutic options to induce recovery.

SEARCH METHODS: We searched articles published in English, French or German language containing keywords related to return of menses after FHA published in PubMed between 1966 and December 2019. Manuscripts reporting data either on the epidemiology or on the physiology of recovery of menses were included and bibliographies were reviewed for further relevant literature. The Strengthening the Reporting of Observational Studies in Epidemiology (STROBE) criteria served to asses quality of observational studies. OUTCOMES: Few studies investigate return of menses and most of them have serious qualitative and methodological limitations. These include (i) the lack of precise definitions for FHA or resumption of menses, (ii) the use of short observation periods with unsatisfactory descriptions, and (iii) the inclusion of poorly characterized small study groups. The comparison of studies is further hampered by very inhomogeneous study designs. Consequently, the exact prevalence of resumption of menses after FHA is 
79 lacking. While weight, body fat and energy availability are associated with the return of menses,

80 psychological factors also have a strong impact on the menstrual cycle and behavior known to increase

81 the risk for FHA. Drug therapies with metreleptin or naltrexone might represent further opportunities to

82 increase chances for the return of menses, but require further evaluation.

83 WIDER IMPLICATIONS: Although knowledge on the physiology of return of menses is presently 84 rudimentary, available data indicate the importance of BMI/ weight (gain), energy balance, and mental 85 health. The physiological processes and genetics underlying the impact of these factors on the return of 86 menses requires further research. Larger prospective studies are necessary to identify clinical parameters 87 for accurate prediction of return of menses as well as reliable therapeutic options.

88

89 KEY WORDS: Recovery of menses; return of menses; restoration of the menstrual cycle; weight; BMI;

90 percentage body weight; eating disorders; physical exercise; stress 
The human menstrual cycle is not only essential for reproduction but also for general well-being (Walf and Frye 2006). Estradiol is needed for adequate bone, cardiovascular, mental, and vaginal health (Levin, Jiang, and Kagan 2018; lorga et al. 2017; Manonai, Chittacharoen, and Theppisai 2004; Rettberg, Yao, and Brinton 2014; Filova et al. 2015; Gordon et al. 2017). Weight loss, eating disorders, exercise, and emotional stressors suppress the activity of the GnRH neuronal network and to produce functional hypothalamic amenorrhea (FHA) (Drew 1961; Mecklenburg et al. 1974; Gadpaille, Sanborn, and Wagner 1987; Berga and Girton 1989; Fries, Nillius, and Pettersson 1974; Frisch and McArthur 1974; Pirke et al. 1989; Warren et al. 1999; Sanchez-Garrido and Tena-Sempere 2013; Roa et al. 2010; Castellano and TenaSempere 2016; Garcia-Garcia 2012; Berga and Naftolin 2012; Bullen et al. 1985; Loucks et al. 1989). A reduction in GnRH drive results in abnormal LH pulse frequency generating cycle disturbances (Berga and Girton 1989; Laughlin, Dominguez, and Yen 1998; Ackerman et al. 2012). By definition, FHA is only diagnosed after anatomic or organic causes of amenorrhea have been excluded.

FHA is responsible for $20-35 \%$ of secondary amenorrhea (American Society for Reproductive Medicine 2008). It occurs in up to $89 \%$ of women with anorexia nervosa and up to $60 \%$ of high-performance athletes

107 (Andersen and Ryan 2009; Watson and Andersen 2003; Roupas and Georgopoulos 2011; Sanborn, Martin, and Wagner 1982; Warren and Perlroth 2001). Because of pre-existing cycle irregularities, the concept of post-pill amenorrhea was abandoned in the early 80ies (Barnhart and Schreiber 2009; Jacobs et al. 1977); $97 \%$ of women experience return of menses within a median time of 32 days after discontinuation of

111 combined oral contraceptives (Davis et al. 2008).

113 FHA is currently treated symptomatically by hormonal replacement therapy to prevent unfavourable 114 health consequences resulting from a lack of estrogens. However, hormone therapy may be associated 115 with an increased risk for breast cancer, venous thromboembolism or stroke (Marjoribanks et al. 2017; 
117 intercourse, intrauterine inseminations or IVF/ICSI and, while highly effective, the latter are costly, time-

118 consuming, and burdensome (Katz et al. 2011).

120 To improve counselling and provide guidance for future research, this review summarizes available

121 knowledge on the factors allowing the return of menses. While focussed primarily on clinical data, we

122 also include a review of the mechanistic and translational aspects of anovulation and the return of menses

123 gained from animal studies. We evaluate (i) which factors determine the recovery of menses and its 124 timing, (ii) how these factors exert their physiological effects, and (iii) whether there are any useful 125 therapeutic options to induce recovery.

\section{Method}

A systematic review of epidemiological data on resumption of menses in humans was performed in accordance with PRISMA (Preferred Reporting Items for Systematic Reviews and Meta-Analyses) criteria (Liberati et al. 2009). A PubMed search from 1966 to February 2020 included the MeSH terms: "re-onset/

131 return or recovery of menses/menstruation", "anovulation", "amenorrhea", combined with, 132 "hypothalamus", "pituitary", "gonadotropin releasing hormone (GnRH)", "GnRH pulse generator", 133 "leptin", "ghrelin", "glucose", "insulin", "cortisol”, "kisspeptin" AND/ OR "influencing factors", "body 134 weight", "energy balance", "eating disorders", "nutrition", "diet", "sports", "stress", "mental health", 135 "posttraumatic stress disorder (PTSD)", "genetics" and/or "treatment", "medication", "stress management", "psychotherapy", "cognitive behavioural therapy (CBT)". A "return of menses" set element AND/ OR a "factor/ physiology" set element were always included in title, abstract or all fields,

138 where capital letters indicate Boolean connectors. All studies were screened by title and abstract. Eligible 139 articles in English, German and French were read, and the relevant information was extracted. Secondary 140 literature from these studies was evaluated for further relevant publications. 
142 FHA is considered to be chronic anovulation not due to any identifiable anatomic or organic causes, i.e. it

143 is a diagnosis of exclusion without any generally accepted diagnostic criteria (Bomba et al. 2007; Gordon

144 2010; Gordon et al. 2017; Genazzani et al. 2010; Sowinska-Przepiera et al. 2015). The differential diagnosis

145 between amenorrhea and FHA please has recently been reviewed (Gordon et al. 2017). Polycystic ovary

146 syndrome (PCOS) was considered a diagnosable cause of amenorrhea and therefore not included within 147 the present review.

148 Any study reporting at least one menstruation after a phase of FHA was considered within this review.

149 The initial systematic search yielded a total of 1424 manuscripts published between 1966 and February

1502020 , with forty-nine manuscripts directly addressing either recovery of menses $(N=34)$ or prolonged

151 amenorrhea $(N=15)$ in humans. Prospective $(N=23)$ and cross-sectional studies $(N=13)$ investigating

152 between 12 and 463 participants formed the majority of research. In addition, five retrospective, six case-

153 control studies and two case reports were analysed.

154 Quality of observational studies was assessed using the "Strengthening the Reporting of Observational 155 Studies in Epidemiology" (STROBE) criteria (von Elm et al. 2007). Case reports were evaluated by the 156 Consensus-based Clinical Case Reporting Guideline Development (CARE) Guidelines (Gagnier et al. 2013).

158 Animal studies investigating the neural mechanisms underlying the impact of metabolic factors on the 159 reproductive axis were considered by AEH. To ensure, no major paper was omitted, recent reviews on the 160 subject from three different research groups were consulted (Ronnekleiv, Qiu, and Kelly 2019; Vazquez, 161 Velasco, and Tena-Sempere 2019; Chianese et al. 2018; Evans and Anderson 2017).

\section{Methodological details of included studies}

164 Resumption of menses and/or risk factors for prolonged amenorrhea were investigated predominantly

165 after the treatment of eating disorders $(\mathrm{N}=29)$, but also in athletes $(\mathrm{N}=13)$ or in stress-related FHA $(\mathrm{N}=$

166 7). Most studies compared anthropometric data (body weight, BMI, body fat) or hormonal parameters

167 between women with and without return of menses aged $<30$ years. Out of the 34 studies directly 
168 investigating the recovery of menses, twelve controlled for well-known hormonal causes of cycle

169 disturbances and related diseases such as PCOS, thyroid diseases, hyperprolactinemia, adrenogenital 170 syndrome, disturbances of the adrenal and pituitary gland or premature ovarian insufficiency. The 171 underlying pathophysiology and the timeline of recovery of menses was rarely addressed. Of the 47 172 observational studies, 13 were of low, 29 of medium, and 5 of high quality (von Elm et al. 2007). The 173 quality of case reports was middle (Kopp-Woodroffe et al. 1999) to high (Mallinson et al. 2013).

\section{Results}

We first define the diagnostic criteria for FHA and the resumption of menses before summarizing the causes of FHA, as their reversal may play a role in the return of menses. We next address potential physical and psychological mechanisms involved in the onset and end of FHA including their interactions. Finally, we will give an overview of currently available treatment options.

\section{Diagnosis of functional hypothalamic amenorrhea (FHA)}

To diagnose $\mathrm{FAH}, 16$ studies relied solely on self-reported amenorrhea (Table 1) while 30 studies evaluated initial cycle status by serum (estradiol, FSH and LH) or urine (estrone glucuronide, pregnanediol glucuronide and $\mathrm{LH}$ ) hormonal parameters. Transvaginal ultrasound of the ovaries was performed in four studies and radiography of the sella turcica in one (Falsetti et al. 2002). A positive response to a GnRH stimulation test was another diagnostic criterion (Pentz and Nakic Rados 2017). FHA was diagnosed after at least three (16 studies) or six (8 studies) months of amenorrhea. Further prerequisites for the diagnosis of FHA were regular menses prior to FHA (Sterling et al. 2009; Christo et al. 2008) or a coincidence of amenorrhea with increased exercise or low weight (Welt et al. 2004). Four studies provided no specific definition of FHA (Bodell and Mayer 2011; Chou et al. 2011; Holtkamp et al. 2003; Rigaud et al. 2011). 
193 The majority of studies ( $\mathrm{N}=24$ ) did not provide any definition of resumption of menses (Table 1 ). Of the

19434 studies explicitly addressing resumption of menses, 31 relied on self-reported bleeding with 12

195 differentiating between one, two or three consecutive spontaneous menstrual cycles as cut-off to 196 diagnose recovery of menses. Four studies required a cycle length of less than 36 days to diagnose recurrence of menses. Further criteria were the exclusion of other potential causes of vaginal bleeding such as infection or trauma. Six studies evaluated either with urine / serum hormonal parameters or by ultrasound whether menstrual cycles were ovulatory.

\section{Body weight, energy availability and return of menses}

The association between body weight/ energy availability and return of menses was explored in eating disorders, or in the context of physical activity (Table 2 and 3, Fig. 1). The majority of the 19 studies support that anthropometric characteristics i.e. BMI, body weight or body composition are associated with resumption of menses (Table 2). However, there are also opposite results (Arimura et al. 2010; El Ghoch et al. 2016).

Eating disorders, body weight and energy availability

Patients who resume menses after eating disorders have a higher BMI $\left(19 \mathrm{~kg} / \mathrm{m}^{2}\right.$ vs $\left.17.5 \mathrm{~kg} / \mathrm{m}^{2}\right)$ or body weight than those who do not (Dempfle et al. 2013; Le Grange et al. 2012). As with individual differences

211 at the onset of amenorrhea, the individual BMI for recovery of menses differs strongly and comparison of 212 different studies is hampered by the use of different weight measures. For example, two-thirds of 213 anorectic girls became amenorrheic at a BMI between 17 and $18.9 \mathrm{~kg} / \mathrm{m}^{2}$ while the remaining third had a 214 normal BMI (Berner et al. 2017). A higher BMI at the onset of amenorrhea is associated with a higher BMI 215 needed to allow return of menses (Berner et al. 2017; Pitts et al. 2014). At or above a BMl of $19 \mathrm{~kg} / \mathrm{m}^{2}$ 216 and $\geq 23 \%$ body fat, about $50 \%$ of women are expected to resume menses (Tinahones et al. 2005). Women 217 with a BMI of $14 \mathrm{~kg} / \mathrm{m}^{2}$ and $11 \%$ body fat still had a probability of $25 \%$ for recovery of menses (Winkler et 
218 al. 2017). Generally, recovery of menses seems to require about $2 \mathrm{~kg}$ more than the weight of the woman

219 at the time at which menses were lost (Golden et al. 1997).

221 Using other weight parameters, menstrual recovery was reported to occur at $91.6 \pm 9.1 \%$ of standard 222 body weight (median body weight adjusted for age, gender, frame size and height) (Frisancho 1984) of 223 (Golden et al. 1997) or $94.9 \pm 9.3 \%$ of expected body weight (EBW = optimal weight related to height 224 and/or age for healthy nutritional status with the lowest rate of mortality) (Faust et al. 2013). In anorectic postmenarcheal girls, a BMI $\geq 27^{\text {th }}$ percentile based on percentiles derived from different national health surveys or a $\mathrm{BMI}$ at the $24^{\text {th }}$ percentile based on BMI measurements from 17 German studies, seems to be necessary for recovery of menses (Dempfle et al. 2013; Golden et al. 2008; Kuczmarski et al. 2000). Interestingly, during spring or summer, anorectic women needed on average $2 \mathrm{~kg}$ less for resumption of menses than during fall or winter (Favaro and Santonastaso 2009).

According to prospective data from anorectic patients, the onset and regularity of menstrual cycles requires between $18 \%$ and $28 \%$ of body fat (El Ghoch et al. 2016; Frisch and McArthur 1974; Frisch 1987; Karountzos et al. 2017; Misra et al. 2006; Tokatly Latzer et al. 2019; Winkler et al. 2017; Pitts et al. 2014) (Table 2). However, even with $36 \%$ body fat, not all women resumed menses (Tinahones et al. 2005). An increase of about $1 \%$ in total body fat at discharge after anorexia treatment was reported to augment the probability of menses by approximately $14 \%$ per year (El Ghoch et al. 2016). Modifications in fat distribution following weight recovery seem to be irrelevant for resumption of menses (Dei et al. 2008; Mayer et al. 2009).

239 Independent from absolute weight, dieting is considered to be a risk factor for amenorrhea (Martini et al. 240 2016). After at least one year of stable normal weight, caloric intake still differed significantly between 241 women with persisting FHA and age-, weight-, as well as body fat- matched control women with a regular 242 cycle (Miller et al. 1998). In addition, eating disorders are closely associated with stress (Smith et al. 2018; 
243 Keski-Rahkonen and Mustelin 2016), which may further increase the risk for prolonged amenorrhea (see 244 below).

245 A few studies have reported no significant association between body fat and the return of menses 246 (Arimura et al. 2010; Golden et al. 1997; Dei et al. 2008; Jacoangeli et al. 2006). Arimura and colleagues 247 (Arimura et al. 2010) reported no resumption of menses immediately after weight recovery but this may have been too short a period of observation as studies supporting an association are based on a longer follow-up period (El Ghoch et al. 2016; Misra et al. 2006; Karountzos et al. 2017; Pitts et al. 2014; Tokatly Latzer et al. 2019). Golden and co-workers (Golden et al. 1997) applied skinfold thickness measurements, which are of rather limited diagnostic quality to evaluate body fat (El Ghoch et al. 2012). The crosssectional studies reporting no association were either small (Jacoangeli et al. 2006) or applied an arbitrary definition of weight recovery (Dei et al. 2008). In summary, the absolute BMI has to be between $17.7 \pm 1.4 \mathrm{~kg} / \mathrm{m}^{2}$ (Pitts et al. 2014) and $22.9 \pm 2.5$ $\mathrm{kg} / \mathrm{m}^{2}$ (Cialdella-Kam et al. 2014) and body fat between $18 \%$ and $28 \%$ to allow resumption of menses. The $\mathrm{BMI}$ at occurrence of amenorrhea is important in setting the individual weight target for recovery of menses. As current research on the association between eating disorders has focused on weight, information is lacking on whether specific eating disorder-related malnutrition is related to amenorrhea.

Prognosis and timing of return of menses after weight recovery: Between $35 \%$ and $54 \%$ of women experience return of menses immediately after achieving normal weight (Arimura et al. 2010; Dempfle et al. 2013; El Ghoch et al. 2016; Winkler et al. 2017; Bodell and Mayer 2011). After a longer treatment/observation period, these rates may rise to $80 \%$ or even $100 \%$ (Golden et al. 1997; Kohmura et al. 1986; Jacoangeli et al. 2006; Tinahones et al. 2005) (Table 3). Studies providing exact information on the time to recovery of menses after weight restoration reported a broad range from $50 \pm 33$ days up to $14 \pm 12$ months until the return of menses (Arimura et al. 2010; Faust et al. 2013; Golden et al. 1997; 
Between $5 \%$ and $68 \%$ of women have been reported to remain amenorrheic after weight recovery

269 (Dempfle et al. 2013; El Ghoch et al. 2016; Golden et al. 1997; Karountzos et al. 2017; Jacoangeli et al. 270 2006; Tokatly Latzer et al. 2019; Favaro and Santonastaso 2009; Misra et al. 2006; Pitts et al. 2014; 271 Kohmura et al. 1986) with between 5\% and 14\% ultimately remaining amenorrheic (Golden et al. 1997; 272 Jacoangeli et al. 2006).

273 According to the guidelines of the Endocrine Society, "the term "functional" hypothalamic amenorrhea 274 implies that correction or amelioration of the causal factors will restore ovulatory ovarian function" 275 (Gordon et al. 2017). However, the return of menses does not necessarily occur after such correction. In previously anorectic adolescents, $86 \%$ experienced the return of menses within six months of stable weight (Jacoangeli et al. 2006). After one year of successful treatment against anorexia, $35 \%-68 \%$ of women resumed menses and 95\% had recovered by year two (Dempfle et al. 2013; El Ghoch et al. 2016; Golden et al. 1997; Golden et al. 2008; Abbate Daga et al. 2012; Bodell and Mayer 2011; Faust et al. 2013; 280 Misra et al. 2006). As all adolescents with premenarchal onset of anorexia remained amenorrheic at the 281 12-month follow-up following weight restoration, the premenarchal onset of eating disorders seems to 282 be an unfavourable factor for recovery of menses (Dempfle et al. 2013). About $5 \%$ of previously anorectic 283 adolescents remain amenorrheic two years after achieving normal weight (Golden et al. 1997). In the 284 study with the longest observation period of 13 years, $97 \%$ of anorectic women resumed their menses 285 (Rigaud et al. 2011). In that study, a BMI $>18.5 \mathrm{~kg} / \mathrm{m}^{2}$ and lack of physical hyperactivity explained $67 \%$ of 286 the variance in return of menses.

287 Although return of menses clearly depends on prerequisites such as BMI or energy availability, individual 288 recovery is difficult to predict. None of the available mathematical models succeed in predicting the exact 289 time for return of menses. Percent body fat and BMI have equal predictive quality but explain only $14 \%$ 290 of the variation in recovery of menses (Winkler et al. 2017). 
Total absolute and percentage weight gain, as well as BMI, are found to differ between athletes with and

294 without recovery of menses (Arends et al. 2012). Nutrition and energy balance also play a role in the 295 return of menses; amenorrheic athletes eat less fat but more carbohydrates and fiber than those with a 296 normal menstrual cycle (Laughlin, Dominguez, and Yen 1998; Cialdella-Kam et al. 2014). Energy availability 297 (defined as the net input of energy remaining after exercise training and energy needed for all other 298 metabolic processes, normalized to $\mathrm{kg}$ of lean body mass (Loucks and Thuma 2003)) is lower in 299 amenorrheic than in eumenorrheic exercising women (Williams et al. 2001), but does not differentiate 300 between ovulatory and anovulatory cycles (Reed et al. 2015). Athletes with amenorrhea often consume 301 too few calories for their energy needs (Melin et al. 2016; Elliott-Sale et al. 2018) and the likelihood of 302 exercise-related menstrual abnormalities seems to vary with the magnitude of the energy deficit 303 (Williams et al. 2015). LH pulsatility has been reported to be disrupted when energy intake in women is 304 less than $30 \mathrm{kcal} / \mathrm{kg}$ lean body weight per day (Loucks and Thuma 2003; Loucks, Kiens, and Wright 2011; 305 Dueck et al. 1996; Reed et al. 2015). Also, an overall reduction of energy by 470 and 810 kcal per day in 306 women with an initial body fat between $15-35 \%$ and a BMI $18-25 \mathrm{~kg} / \mathrm{m}^{2}$ increases the risk for menstrual 307 cycle disturbances (Williams et al. 2015). Menstrual function may already stop at energy availabilities 308 above this threshold, but specific causes for these differences have not be identified as yet (Lieberman et 309 al. 2018; Reed et al. 2015; Holtzman and Ackerman 2019). It is possible that age-related physiological 310 differences during adolescence may influence actual parameter thresholds. However, very few studies 311 have so far addressed the identification of clear cut-off values and related influencing factors. 312 Unfortunately, the exact extent of physical activity and details of nutrition and nutritional supplements 313 are only assessed in a few studies, which makes comparison of results difficult.

314 Athletes with FHA also show a significantly lower resting energy expenditure compared to eumenorrheic 315 athletes, but part of this difference may result from discrepancies in initial and actual body weight or BMI 316 between study participants (Sterling et al. 2009; Christo et al. 2008). 
319 energy availability by nutritional supplements, and a decrease in energy expenditure, increases the 320 chances for resumption of menses (Table 3) (Arends et al. 2012; Cialdella-Kam et al. 2014; Kopp321 Woodroffe et al. 1999; Lagowska et al. 2014; Mallinson et al. 2013). In athletes close to normal weight, 322 amenorrhea may reverse when training is reduced (Benson, Engelbert-Fenton, and Eisenman 1996; 323 Warren 1980). With adequate calorie-intake, menses are expected to reoccur in $75 \%-100 \%$ of women 324 (Kopp-Woodroffe et al. 1999; Mallinson et al. 2013; Cialdella-Kam et al. 2014). An appropriately balanced 325 diet with the simultaneous limitation of training volume and intensity is therefore the main tool to reduce 326 menstrual disorders in athletes (Nattiv et al. 2007; Manore, Kam, and Loucks 2007) with percent weight 327 gain being a significant positive predictor for recovery of menses (Cialdella-Kam et al. 2014).

328 After adjusting weight and energy balance, the time until recovery of menses varied from 11 weeks to 33 329 months (Arends et al. 2012; Cialdella-Kam et al. 2014; Kopp-Woodroffe et al. 1999; Mallinson et al. 2013). 330 While one study showed a correlation between the duration of amenorrhea and recovery of menses 331 (Cialdella-Kam et al. 2014), another study did not support such association (Arends et al. 2012).

\section{Comparison of women with eating disorders to women with excessive exercise}

334 The relevance of different factors involved in the resumption of menses seems to vary in relation to 335 factors involved in the initiation of amenorrhea. In eating disorders, the extent of weight and/or fat gain 336 seems to be particularly important for recovery (El Ghoch et al. 2016; Dempfle et al. 2013) whereas in 337 normal-weight athletes, adequate energy intake seems to play the major role (Reed et al. 2015). Women 338 with eating disorders show addictive and obsessive-compulsive traits, that can manifest in excessive 339 physical activity (Davis and Claridge 1998). Amenorrhea is more prevalent among athletes with eating 340 disorders (Peric et al. 2016), and 39\%-48\% of women with eating disorders also engage in excessive 341 exercise, i.e. there is a common overlap of risk factors for prolonged amenorrhea (Freimuth, Moniz, and $342 \operatorname{Kim} 2011)$. 
346 There is a well-documented regulatory influence of energy balance on fertility. For the most part this is 347 brought about by circulating energy-related hormones and metabolites that modulate the functioning of 348 central hypothalamic networks controlling the secretion of gonadotropin-releasing hormone (GnRH).

349 Mammalian fertility is governed by a neural network that integrates a range of internal and external cues to control the release of $\mathrm{GnRH}$ that, in turn, generates pulsatile and surge profiles of gonadotropin secretion (Fig. 2) (Herbison 2016). Although pulsatile gonadotropin secretion occurs throughout the menstrual cycle, the frequency and amplitude of pulses change across the cycle to ensure the correct maturation of developing follicles (Herbison 2018). Studies in animal models have now demonstrated that a population of kisspeptin neurons located in the hypothalamic arcuate/infundibular nucleus operate as the "GnRH pulse generator" by activating the GnRH neurons to generate pulsatile gonadotropin secretion (Herbison 2018; Plant 2019). It is clear from both animal and human studies that chronic and acute energetic stressors can result in a marked reduction in LH pulsatility (Loucks, Verdun, and Heath 1998; Hilton and Loucks 2000; Wade and Jones 2004; Loucks and Thuma 2003). In addition to pulses, the hypothalamus and pituitary generate the mid-cycle LH surge that initiates ovulation. Disturbances of either pulsatile or surge profiles of gonadotropin hormone secretion can suppress fertility.

Investigators have now discovered a wide range of circulating factors that inform the brain on the metabolic and energy status of the body. Whilst these hormones are primarily driving appropriate central energy regulation through appetite and energy expenditure, the same signals are thought to be used to regulate the GnRH neuron network and, accordingly, the menstrual cycle (Evans and Anderson 2017; Fernandez-Fernandez et al. 2006; Navarro and Kaiser 2013). Discussed below are the roles of leptin, ghrelin and insulin, considered to be the primary peripheral factors signalling information on body weight and energy availability to the GnRH neuron network. The impact of activating stress pathways, often not easily separated from the energy deficit itself, is also considered. 
371 The vast majority of work in this field has examined how energy insufficiency/stress operates to suppress 372 pulsatile gonadotropin secretion resulting in cycle abnormalities and infertility. Unfortunately, very little 373 work has examined the return of fertility with the presumption being that it is a reversal of the mechanism 374 that initiates the infertility generated by energy stress. Perhaps surprisingly, the resumption of pulsatile 375 LH secretion in re-fed, acutely energetically-stressed women is much slower (taking up to one week) than in men or in experimental animals examined to date (Loucks, Verdun, and Heath 1998; Cameron 1996; Szymanski et al. 2007).

Leptin: Secreted by adipocytes into the circulation, leptin signals body fat stores with elevated levels acting on the hypothalamus to reduce feeding and increase energy expenditure. Leptin concentrations also fluctuate on a shorter time scale unrelated to weight or body fat, being reduced with fasting (Ahima et al. 1996; Flier 1998; Grinspoon et al. 1997). Women with anorexia and exercise-induced amenorrhea are hypoleptinemic (Audi et al. 1998; Jimerson et al. 2000; Mantzoros et al. 1997; Miller et al. 1998). Interestingly, even after controlling for body fat, women with exercise- or eating-related FHA have significantly lower leptin levels than those of their ovulatory counterparts (Miller et al. 1998; Warren et al. 1999; Andrico et al. 2002). A leptin level of $1.85 \mathrm{ng} / \mathrm{ml}$ (Reference $4.1-25 \mathrm{ng} / \mathrm{ml}$ ) appears to be the critical level for amenorrhea (Kopp et al. 1997). Values above this lead to an increase of LH (Holtkamp et al. 2003) and more than $20 \%$ of amenorrheic women recover menses at levels $>1.85 \mathrm{ng} / \mathrm{ml}$ (Tinahones et al. 2005). However, a cross-sectional study found no differences in leptin levels or BMI between two groups of anorectic patients with and without amenorrhea (Audi et al. 1998). Furthermore, the reinstatement of pulsatile LH secretion by refeeding chronically food-restricted ewes was found to be unrelated to circulating leptin concentrations (Nakamura, Osonoi, and Terauchi 2010).

393 The mechanisms through which leptin controls fertility are multifaceted and may involve peripheral as 394 well as central actions. For example, high leptin levels enhance oocyte nuclear and cytoplasmic 395 maturation and affect follicle rupture and corpus luteum formation (Craig et al. 2004; Ruiz-Cortes et al. 
2003). However, studies in rodents indicate that the primary impact of leptin on fertility likely arises

397 through central mechanisms. The deletion of leptin receptors from just the brain results in infertility

398 (Quennell et al., 2009) and actively blocking leptin signalling in the brain reduces pulsatile LH secretion

399 (Carro et al., 1997). These effects are often considered to be permissive in the sense that they enable 400 normal functioning of the GnRH neuron network rather than actually determining its magnitude or mode 401 of action.

402 Many studies in animal models have tried to establish the neural pathway through which leptin influences GnRH neurons. As GnRH and kisspeptin neurons seem unlikely to express functionally significant leptin receptors themselves, attention has focussed upon indirect mechanisms by which circulating leptin modulates the activity of neurons that project to and control the kisspeptin and/or GnRH neurons (Evans and Anderson 2017; Navarro and Kaiser 2013). While roles have been proposed for leptin to operate through premammilary nucleus neurons (Donato et al. 2011) and GABA neurons in the brain (Zuure et al. 2013) to control GnRH secretion, most evidence favours an effect of leptin on neuropeptide Y/agoutirelated peptide (NPY/AgRP) neurons (Ronnekleiv, Qiu, and Kelly 2019). These are the same cells 410 implicated in the potent actions of leptin on energy metabolism. As such, it is envisaged that low leptin 411 levels act through NPY/AgRP neurons to both increase feeding and disable the normal menstrual/estrous cycle. Precisely how the leptin-sensing NPY/AgRP neurons impact upon GnRH secretion remains unclear with the most likely pathway being through direct the control of the kisspeptin neuron pulse generator 414 (Hessler, Liu, and Herbison 2020). The resumption of menses in FHA woman may result from the re415 establishment of normal energy balance leading to normalised leptin levels and consequently reduced NPY/AgRP neuron activity permitting normal pulsatile GnRH secretion.

418 Insulin \& glucose: Diet and negative energy balance associated with FHA generate a hypometabolic state 419 that includes, among other abnormalities, lowered circulating insulin levels (Laughlin and Yen 1996). As 420 such, insulin is one potential pathway through which the menstrual cyclicity is regulated in women with 421 exercise- or diet-related FHA. Indeed, fasting insulin levels are higher in women with a history of eating 

et al. 2017; Tinahones et al. 2005). A similar association has been confirmed following weight-recovery (defined as an increase in weight $>85 \%$ of the initial weight before amenorrhea) (Dei et al. 2008), during the 8 - 26 months treatment phase for an eating disorder (Karountzos et al. 2017) and in the early follicular phase in women with resumption of menses (Tinahones et al. 2005). However, studies in male monkeys indicate that the key factor underlying the return of normal LH pulsatility following a nutritional stress is the increase in caloric intake independent of glucose or insulin (Cameron 1996).

It is likely that insulin operates at multiple levels of the reproductive axis to exert a modulatory effect upon fertility. Unlike leptin, there is much less certainty that insulin actions in the brain are necessary or critical. Whereas an early study reported that the deletion of insulin receptors selectively from the brain of mice resulted in mild hypogonadism (Bruning et al. 2000), another study found no reproductive abnormalities (Evans and Anderson 2017). Further, the deletion of insulin receptors selectively from GnRH or kisspeptin neurons, or a range of other neuronal phenotypes, has been found to have no impact upon fertility in mice (Qiu et al. 2013; Divall et al. 2010; Evans and Anderson 2017). Interestingly, over nutrition resulting in obesity-induced infertility in mice appears to be dependent, at least in part, upon insulin signalling at the GnRH neuron (Divall et al. 2010), pituitary gland (Brothers et al. 2010) and ovary (Wu et al. 2012). It is unknown whether this represents a similar mechanism to the cycle disturbances resulting from energy deficit.

Glucose concentrations themselves may represent an independent pathway through which energy stress

441 suppresses the menstrual cycle. For example, reducing glucose availability within the brain suppresses 442 pulsatile LH secretion in experimental animals (Murahashi et al. 1996; Lado-Abeal et al. 2002) and binge 443 eating or binge-purge behaviour in humans is associated with a higher risk for FHA (Johnson and Whitaker 444 1992). Differentiating any role of glucose from insulin in energy stress-evoked FHA can be challenging, but 445 available evidence is equivocal regarding whether glucose may be more or less important than alterations 446 in insulin secretion (Roland and Moenter 2011; Szymanski et al. 2007; Cameron 1996). Precisely where 447 glucose acts to modulate the menstrual cycle remains unclear given the ubiquitous requirement for 
glucose and multiple different sensors that could be involved. Peripherally, glucose deficiency can compromise the ability of the oocyte to reach the second metaphase, to extrude the first polar body (Dominko and First 1997), and to achieve the blastocyte stage (Dan-Goor et al. 1997). There is also evidence demonstrating that glucose modulates the electrical excitability of GnRH neurons in a direct manner through AMPkinase, as well as indirectly through glucose-sensitive inputs from neurons located in the brainstem (Roland and Moenter 2011). Thus, the return of a normoglycemic state to women with FHA may contribute to the return of menses through direct glucose actions at multiple and varied sites throughout the reproductive axis.

Ghrelin: Ghrelin acts as a signal of starvation and energy insufficiency and is secreted by the stomach in a fluctuating pattern with elevated concentrations occurring prior to meals (Tena-Sempere 2013). Unsurprisingly then, ghrelin concentrations are found to be continuously elevated in women suffering 460 from chronic undernutrition and exercise-induced amenorrhea (De Souza et al. 2004; Schneider, Monaco, 461 and Warren 2008; Tolle et al. 2003; Christo et al. 2008). In this case, an energy deficient state results in 462 elevated ghrelin levels (compared with reduced leptin, insulin and glucose concentrations) and evidence 463 indicates that elevated ghrelin levels suppress gonadotropin secretion (Kluge et al. 2012). Hence, the 464 elevated ghrelin levels found in women with FHA may represent another pathway contributing to their suppressed fertility (Christo et al. 2008).

466 In common with the other potential hormonal mediators highlighted above, ghrelin has multiple potential 467 sites of action within the reproductive axis. Ghrelin receptors (GHS-R) are widely expressed in the ovary, 468 pituitary and within the regions of the hypothalamus involved in the control of GnRH secretion (Gaytan 469 et al. 2003; Gaytan et al. 2005; Tena-Sempere 2007). However, animal studies indicate that ghrelin 470 signalling is not itself essential for the suppression of cycles as the deletion of the ghrelin receptor in mice 471 has no impact on fertility or feeding (Sun, Ahmed, and Smith 2003). It does, however, appear to modulate 472 glucose sensing, insulin sensitivity and the stress response (Sun et al. 2008; Sominsky et al. 2017) and may, 473 through these mechanisms, have some role in indirectly modulating the menstrual/estrous cycle (Evans 
and Anderson 2017).

Other hormones: While the discussion above considers what are thought to be the primary hormonal signals modulating fertility, women with energy-related FHA exhibit multiple other endocrine abnormalities. For example, FT3, FT4, and TSH are commonly decreased in amenorrheic women with eating disorders and increase after resumption of menses (Dei et al. 2008; Karountzos et al. 2017; Tinahones et al. 2005). Whether and how thyroid hormones are related to the resumption of menses remains unclear. Similarly, levels of growth hormone and insulin-growth factor-1 (IGF1) are reduced in FHA (Bomba et al. 2007; Miller et al. 2004). An IGF-1 level of $>342.8 \mathrm{ng} / \mathrm{ml}$ has been proposed to be a predictor for return of menses (Cominato et al. 2014), although two other studies have found no positive correlation (Falsetti et al. 2002; Arimura et al. 2010).

Psychological and psychogenic factors

The hypothalamic neurons regulating GnRH pulses not only respond to metabolic conditions but also to psychological and psychogenic factors (Drew 1961; Mecklenburg et al. 1974; Gadpaille, Sanborn, and Wagner 1987; Berga and Girton 1989; Fries, Nillius, and Pettersson 1974; Frisch and McArthur 1974; Pirke et al. 1989; Warren et al. 1999; Sanchez-Garrido and Tena-Sempere 2013; Roa et al. 2010; Castellano and Tena-Sempere 2016; Garcia-Garcia 2012; Berga and Naftolin 2012; Bullen et al. 1985; Loucks et al. 1989). Emotional stressors as measured by both subjective and objective parameters increase the risk for FHA in humans and in animals (Sanders and Bruce 1999; Gordley et al. 2000; Bomba et al. 2007; Brown et al. 1983; Kondoh et al. 2001; Facchinetti et al. 1993; Harlow and Matanoski 1991). In adolescent girls, changing school, initiating sexual activity, breaking up with a boyfriend, chronic illness, death of a friend or family member, and family conflicts may result in FHA (Bomba et al. 2007). Psychological risk factors that chronically activate the HPA axis include perfectionism, high need for social approval, conditional 498 love and/ or unrealistic expectations of self and others (Berga and Girton 1989; Giles and Berga 1993; 
to be more anxious, stubborn, and perfectionist (Shanan et al. 1965). It is possible that sleep deprivation

501 may exacerbate this by further activating the HPA axis to induce anovulation and amenorrhea (Lateef and

502 Akintubosun 2020). These effects are also seen in monkey models where a change of social environment,

503 or disruptive social interactions with group members can generate amenorrhea (Michopoulos et al. 2009;

504 Bethea, Centeno, and Cameron 2008; Bethea et al. 2005; Wagenmaker et al. 2009; Adams, Kaplan, and

505 Koritnik 1985).

506 Traumatic events such as sexual assault, incarceration or natural disasters may induce post-traumatic stress disorders (PTSD) (Beaglehole et al. 2018; Leeners et al. 2007), which is another risk factor for FHA evident (Sydenham 1946). Incarcerated women show a higher prevalence of amenorrhea, with women reporting additional stress factors such as childhood physical or sexual abuse, economic deprivation or 512 coming from a racial and ethnic minority being at increased risk (Allsworth et al. 2007).

513 It is also evident that behaviours such as over-exercise or restricting eating may reflect an underlying 514 mental or psychiatric disease (Giles and Berga 1993; Marcus, Loucks, and Berga 2001; Berga 2008). For 515 instance, amenorrheic runners were found to suffer significantly more often from major affective or eating disorders than menstruating runners (Gadpaille, Sanborn, and Wagner 1987). Also women with anxiety disorders or depression have been found to be at increased risk for FHA (Fava et al. 1984; Joffe et al. 2006; Lawson et al. 2009).

Women with FHA often display combinations of psychological factors that can activate stress responses, 521 induce metabolic disturbances, and/or result in excessive exercising (Marcus, Loucks, and Berga 2001; 522 Giles and Berga 1993; Faust et al. 2013). In rhesus monkeys, the combination of low-level psychosocial 523 stress and moderate energy imbalance resulted in a higher proportion of abnormally long or anovulatory 524 cycles than either stressor alone (Williams, Berga, and Cameron 2007; Williams et al. 2001). Thus, psychological, psychogenic and metabolic stressors act synergistically in compromising reproduction 
(Marcus, Loucks, and Berga 2001; Giles and Berga 1993; Berga, Daniels, and Giles 1997; Warren et al. 1999; Williams, Berga, and Cameron 2007; Berga 2008). In line with these findings, severe mental or 528 infectious diseases such as HIV or Ebola infection have been found to add to the risk for FHA (Fava et al. 529 1984; Cejtin et al. 2018; Godwin et al. 2019). On this background, the current SARS-CoV-2 pandemic will probably also influence the prevalence of FHA.

Substantial investigation has focused on examining the mechanisms through which immune, nutritional and psychological stressors impact upon the reproductive axis (Li and O'Byrne 2015). Stress activates multiple neural axes and results in elevated corticosteroid and prolactin concentrations. All of these factors, in turn, can impact upon the functioning of the GnRH neuronal network (Li and O'Byrne 2015; Mastorakos, Pavlatou, and Mizamtsidi 2006; Meczekalski et al. 2008; Williams, Berga, and Cameron 2007; Berga and Girton 1989; Dobson et al. 2003). In many cases, it is difficult to tease apart the impacts of nutritional and psychological stressors on fertility with a synergism between the two in operation (Berga 1997; Fioroni et al. 1994; Shanan et al. 1965; Chand and Lovejoy 2011; Mendelson 2013).

541 Cortisol: High cortisol levels are well known to be associated with amenorrhea (Berga, Daniels, and Giles 542 1997; Suh et al. 1988; Berga and Girton 1989; Brundu et al. 2006): Athletes with FHA as well as those with eating disorders and amenorrhea have higher serum cortisol levels than women with a menstrual cycle 544 (Villanueva et al. 1986; Laughlin, Dominguez, and Yen 1998; Ackerman et al. 2012). Administration of 545 hydrocortisone reduces LH pulse frequency during the follicular phase of otherwise eumenorrheic women 546 (Saketos, Sharma, and Santoro 1993). Elevated circulating corticosteroids reduce LH pulse amplitude 547 (Petraglia et al. 1987; Olster and Ferin 1987; Breen et al. 2008; Dudas and Merchenthaler 2002; Saketos, 548 Sharma, and Santoro 1993) and suppress LH pulse frequency through an unknown central mechanism 549 (Ralph et al. 2016). Traumatic family events (sexual abuse, parental conflict, separation or death) have are 550 associated with elevated cortisol levels that can persist beyond the traumatic period (Flinn et al. 2011; 551 Jacobs, Boynton-Jarrett, and Harville 2015) and consequently present a long-term risk factor for FHA. 
Cortisol seems to be one of the most important factors in return of menses. In women with a history of eating disorders, and even after weight gain, serum levels of fasting cortisol tend to be lower in women with return of menses compared to those without (Dei et al. 2008; Karountzos et al. 2017; Misra et al. 2006; Pitts et al. 2014; Tinahones et al. 2005; Arimura et al. 2010). Other studies confirmed significant differences in cortisol levels between women with and without return of menses (Falsetti et al. 2002; Jacoangeli et al. 2006; Miller et al. 1998) and two studies identified low serum cortisol levels as a predictor for the return of menses (Arimura et al. 2010; Falsetti et al. 2002). Furthermore, women with a return of menses after cognitive behavioral therapy had cortisol levels comparable to those of eumenorrheic women (Berga, Daniels, and Giles 1997).

$\underline{\mathrm{CRH}}$ : CRH suppresses pulsatile LH secretion but the pathway through which activated CRH neurons inhibit GnRH secretion remains unclear (McCosh, Breen, and Kauffman 2019; Li and O'Byrne 2015). There is little evidence for a direct modulation of GnRH neurons by $\mathrm{CRH}$ although effects of $\mathrm{CRH}$ on kisspeptin neurons may exist (Raftogianni et al. 2018; McCosh, Breen, and Kauffman 2019).

Prolactin: Prolactin is released in response to stress in humans and animals (Levin, Jiang, and Kagan 2018; Armario et al. 1996; Schedlowski et al. 1992; Theorell 1992; Sonino et al. 2004; Sobrinho 2003). Animal studies show that prolactin acts through kisspeptin neurons to suppress pulsatile GnRH secretion and infertility due to hyperprolactinemia can be reversed to some extent by treatment with kisspeptin (Sonigo et al. 2012). Prolactin also raises secretion of ACTH and augments the adrenal cortex's sensitivity to ACTH, thus resulting in high corticosterone release even with low levels of ACTH (Weber and Calogero 1991).

\section{$\underline{\text { Adrenergic pathways }}$}

Acute stress results in the elevated secretion of catecholamines from the adrenal medulla and the activation of brainstem adrenergic neurons (William Tank and Lee Wong 2014). The effects of adrenaline and noradrenaline on LH secretion have been known for many decades (Sawyer 1975) but the precise 
mechanisms through which they modulate GnRH secretion remain unclear (Herbison 2015). In general, adrenergic inputs to the $\mathrm{GnRH}$ neuronal network are thought to exert a permissive role in enabling the network to function optimally for both pulsatile and surge secretion (Herbison 1997; Anselmo-Franci et al. 1997; Gallo et al. 1989, Scott and Clarke, 1993; Goodman et al., 1995). Nevertheless, in gonadectomised animals, noradrenaline consistently suppresses pulsatile LH secretion (Herbison 1997). Electrophysiological studies in mice have revealed that the activation of adrenergic receptors on GnRH neurons was exclusively inhibitory (Han and Herbison 2008). Thus, it seems likely that the brainstem adrenergic neurons innervate multiple components of the GnRH neuronal network where they may exert different effects depending upon their level of activation (Herbison 1997). For example, under states of heightened activation, they may provide a predominant direct inhibition of GnRH neurons to aid in the suppression of pulsatile LH secretion.

The likelihood of occurrence of FHA and return of menses may be influenced by an individual's sensitivity 591 to stress. Evidence in humans and monkeys indicates that alterations in brain serotonin transmission play 592 a role in determining am individuals sensitivity to stress (Bethea, Centeno, and Cameron 2008; Tancer et 593 al., 1994; Ressler and Nemeroff, 2000; Bhagwagar et al., 2002). Stress-sensitive monkeys were found to have diminished serotonergic activity and administration of a serotonin reuptake inhibitor (citalopram) improves stress resilience (Lima et al. 2009; Bethea et al. 2005). Human and animal studies have also indicated that a serotonin transporter gene variant is involved in individual stress susceptibility and related suppression of LH secretion (Caspi et al. 2010; Caspi et al. 2003; Grabe et al. 2005; Michopoulos 598 et al. 2009). Notably, a decrease in ovarian steroid hormone concentrations was found to suppress 599 serotonin neural function in monkeys (Bethea et al. 2002; Bethea et al. 2005) but it remains unclear to 600 what extent circulating steroid levels are involved in maintaining FHA in women. Women with greater 601 stress resilience show a reduced risk for irregular menstrual cycles when experiencing low to moderate 602 chronic stress (Palm-Fischbacher and Ehlert 2014). However, no studies evaluating stress-resilience in the 603 context of resumption of menses have been conducted so far. 
606 Cigarette smoking is associated with higher rates of menstrual disorders (Buck et al. 1997; Howe et al. 1985). Several biologic mechanisms have been proposed to underlie this, such as actions on the 608 hypothalamic-pituitary-ovarian axis, a direct toxic effect on the ovary, and alterations in peripheral 609 estrogen production (Weisberg 1985). In a study of 2544 college students, cigarette smoking showed a 610 dose-dependent relationship with the risk for FHA (Johnson and Whitaker 1992). Smoking more than one 611 packet of cigarettes per day was associated with a 1.96 increased relative risk for persisting amenorrhea. 612 Unfortunately, no information was available on the lifetime duration of smoking. The well-established 613 association between smoking and lower BMI (Rasky, Stronegger, and Freidl 1996) is a potential confound 614 but student smokers in that study had the same relative weight as non-smokers.

615 The effect of alcohol intake on the menstrual cycle has not been clearly established (Grodstein, Goldman, 616 and Cramer 1994; Mello 1988). Recent moderate alcohol intake does not appear to have adverse short617 term effects on menstrual cycle function (Schliep et al. 2015; Shilaih et al. 2017). The only study 618 investigating alcohol intake in the context of prolonged amenorrhea showed no association between 619 alcohol consumption and persistence of FHA (Johnson and Whitaker 1992). These findings have to be 620 interpreted with caution as alcohol intake was self-reported.

Genetic factors

623 Genetic factors influence age at menarche (Dvornyk and Waqar ul 2012) and at menopause (Voorhuis et 624 al. 2010) and will very likely also be involved in the regulation of the menstrual cycle. Rare gene variants associated with idiopathic hypogonadotropic hypogonadism in women with hypothalamic amenorrhea, may influence susceptibility to functional changes in GnRH secretion (Caronia et al. 2011). Also, in comparison to regularly menstruating runners, runners with FHA reported more eating disorders or major affective disorders in close kinship (Gadpaille, Sanborn, and Wagner 1987). 
631 Medical treatment options for facilitating the recovery of menses include gonadal hormonal therapy 632 (Falsetti et al. 2002; Genazzani et al. 2012; Shen, Xu, and Lin 2013), recombinant human leptin 633 (metreleptin) (Chou et al. 2011; Welt et al. 2004) or opioid receptor blockers (naltrexone) (Genazzani et 634 al. 1995). Altogether, six prospective studies are available ( 3 of low, 1 of middle and 2 of high quality).

\section{Medication}

637 Estrogen: The association between estrogens and female weight has been previously reported (Leeners 638 et al. 2017). An increase in estradiol levels resulting from follicular maturation and conversion of 639 androgens to estrogens in fat tissue (associated with weight gain) is confirmed in all of the studies 640 investigating hormonal levels in resumption of menses (Arimura et al. 2010; Audi et al. 1998; Barakat et 641 al. 2016; Cominato et al. 2014; Holtkamp et al. 2003; Jacoangeli et al. 2006; Karountzos et al. 2017; Pitts 642 et al. 2014; Tokatly Latzer et al. 2019). Estrogen increases GnRH receptor gene expression and enhances 643 the ability of FSH to induce expression of LH receptors and promote follicular growth (Turzillo, Nolan, and 644 Nett 1998; Richards et al. 1976). This has generated the hypothesis that the pituitary response to GnRH 645 and the ovarian response to gonadotropin could be reinforced with estrogen. However, studies evaluating 646 this hypothesis failed to show any effect on the likelihood of recovery of menses (Falsetti et al. 2002; 647 Genazzani et al. 2012; Shen, Xu, and Lin 2013).

Metreleptin: Recombinant human leptin (metreleptin) facilitated the recovery of menses in women with FHA due to low body weight, excessive exercise or unspecified reasons (Chou et al. 2011; Welt et al. 2004).

651 With two daily subcutaneous doses $(0.08-0.12 \mathrm{mg} / \mathrm{kg}$ body weight) to mimic normal diurnal patterns, 652 recovery of menses occurred after 28 days up to 32 weeks (Welt et al. 2004; Chou et al. 2011; Wong et 653 al. 2004). In women, without return of menses during the study period, continuous improvement of 654 follicular maturation was confirmed by ultrasound and laboratory parameters (Welt et al. 2004). 655 Important adverse effects of metreleptin application include a decrease in appetite that is counter- 
productive to energy status (Welt et al. 2004; Chou et al. 2011). Although results are promising, further

657 investigations are necessary to determine the efficacy and safety of metreleptin treatment including dose-

658 finding and treatment duration studies in different background characteristics.

660 Naltrexone: The long-acting opioid receptor blocker naloxone increases LH pulse frequency and amplitude 661 in amenorrheic women (Quigley et al. 1980; Khoury et al. 1987) and, as such, naltrexone has been tested to induce the recovery of menses. Administration of 50-150 mg/d was found to have no effect (Remorgida et al. 1990), a moderate effect (Armeanu, Berkhout, and Schoemaker 1992), or full return of menses (Wildt and Leyendecker 1987; Wildt et al. 1993). In the most recent placebo-controlled study, 24 (80\%) women with FHA due to weight loss reported menstrual bleeding within 90 days after initiation of naltrexone therapy (Genazzani et al. 1995). After three months of treatment, LH plasma levels and pulse amplitude increased whereas FSH plasma levels did not show any change. The recovery of menstrual cycles occurred prior to weight gain, suggesting that naltrexone had a central effect independent from body weight gain. Six months after naltrexone discontinuation, $75 \%$ of the women were still eumenorrheic. Although only minor side effects such as nausea at the beginning of treatment have been reported, further studies are necessary to determine the efficacy and safety in a larger sample of women with FHA distinguished by its trigger.

\section{Psychotherapeutic interventions}

675 Women with FHA, especially those with eating disorders, often experience fear of weight gain, concerns about dieting, weight judgements of others, perfectionistic performance standards, tendencies to engage in binge eating, excessive exercise, or depressive symptoms (Fries, Nillius, and Pettersson 1974; Faust et al. 2013; Brambilla et al. 2003; Favaro and Santonastaso 2009; Giles and Berga 1993; Marcus, Loucks, and Berga 2001). Many of these characteristics can effectively be treated by CBT (Berga and Loucks 2006;

680 Berga et al. 2003; Michopoulos et al. 2013). CBT may successfully modify eating and exercise patterns, 681 maladaptive attitudes concerning body image and weight regulation as well as problem-solving 
techniques (Marcus, Loucks, and Berga 2001; Giles and Berga 1993; Mountjoy et al. 2018; Pauli and Berga 2010). CBT has been shown to promote the return of menses alongside the recovery of cortisol or leptin levels (Berga, Daniels, and Giles 1997; Berga et al. 2003; Michopoulos et al. 2013; Berga and Loucks 2006). Besides CBT, hypnotherapy may be helpful in women with FHA (Tschugguel and Berga 2003). Coping skills such as relaxation, distress tolerance, meditation and mindfulness or yoga provided further positive effects (Katterman et al. 2014; Rani et al. 2011; Goyal et al. 2014; Hall et al. 2016; Berkman et al. 2006), but have not directly been investigated in their effect on recovery of menses.

\section{Discussion}

While disturbances of the menstrual cycle in association with weight loss and reduced energy balance are relatively well understood, knowledge on which conditions and whether menses recovers after FHA is rather limited. Recently published guidelines of the Endocrine Society provide well-founded recommenddations for the diagnosis of FHA as well as the treatment of its consequences such as bone loss, infertility or eventual cardiovascular impairment (Gordon et al. 2017). The present review focusses on the return of menses, i.e. expand these guidelines into the physiology of recurrence of the menstrual cycle and options to end FHA.

Providing a comprehensive account of the return of menses after FHA is challenged by the many methodological differences used in study designs examining this issue and the difficulties in teasing out the impact of the influencing factors. Research groups use various definitions of FHA and also of the return of menses; for example, with regard to the total number of cycles requested, the regularity of cycles, or the presence of ovulation. Only 11 of the 31 studies exploring recovery of menses after FHA presented a definition of the return of menses and often the duration of initial amenorrhea is not reported. Most studies do not differentiate between full ovulatory cycles and partial recovery.

In addition, the conditions to be met to initiate the observation phase [i.e. body weight/BMI, energy 
intake/expenditure, etc.] when return of menses can justifiably be expected, are often either not defined,

708 not confirmed, or not controlled for stability during the observation phase. A further important point is 709 the marked variation in the total length of the follow-up period.

710 We also note that many different approaches have been used to define and evaluate influencing factors

711 such as measures of weight/body fat, energy balance, nutrition, psychological and lifestyle factors. Often,

712 studies have not controlled for well-known hormonal causes of cycle disturbances and endocrine

713 diseases. This is particularly important as, at present, we cannot distinguish between causes and

714 consequences for most gut hormones, or other laboratory parameters. Differences in study groups

715 related to causes of FHA, age, ethnicity, psychological background conditions and small sample sizes

716 further challenge the generalizability of findings.

717 Only twelve studies had a prospective design and currently no prospective longitudinal studies exist with 718 adequately powered study groups that control for relevant confounders to allow a reliable estimation of 719 the frequency and timing of recovery of menses. Consequently, our knowledge of the prevalence of 720 recovery of menses come from studies that are of a very limited quality. Today, we cannot identify women 721 with an increased risk for long-term FHA even after weight/BMI and energy availability have been 722 normalized. It is very likely that psychological factors and stress are involved in those women returning to 723 normal weight without a return of menses (Gordon et al. 2017), but presently no studies on success rates 724 of treatment concepts including both organic and psychological factors are available. Therefore, we can 725 not as yet answer the question if the return of menses can be reliably achieved with adequate treatment.

727 While there is abundant research on the onset of the cycle during puberty and the initiation of 728 amenorrhea in the case of weight loss or unfavourable energy balance, literature on the physiology of 729 recovery of menses is virtually non-existent. Animal studies have allowed understanding of the regulation 730 of the pulse generator and how different gut hormones interact with the GnRH neuronal network, but 731 more research is needed, to better understand the regulatory mechanisms involved in the recovery of 732 menses in women. 
733 Although study designs vary considerably with regard to parameters and techniques chosen, research

734 findings consistently support the importance of maintaining of a stable normal weight, a minimum 735 amount of body fat and adequate energy availability for recovery of menses. However, we lack a reliable 736 basis to suggest target weights or energy balance that would allow the recovery of menses in individual 737 women. Also, we cannot predict if the menstrual cycle recovers after the normalization of weight and energy balance in individual women and how lifestyle or psychological factors are involved. Studies examining the association between sport and return of menses show higher chances of recovery in normal weight women when energy availability increases in most but not in all studies. The small number of study participants, self-reported food intake (known to be biased by underreporting) and limited precision of the evaluation of energy balance might explain differences in findings.

The calculation of nutritional needs based on total energy expenditure and sufficient carbohydrate and protein requirements derived from individual goals and sport-specific regimens is the major factor promoting the return of menses in athletes (Arends et al. 2012; Cialdella-Kam et al. 2014; Kopp-Woodroffe et al. 1999; Lagowska et al. 2014; Mallinson et al. 2013; Reed et al. 2015). In contrast, weight recovery is the most important factor in women with FHA due to eating disorders (Dempfle et al. 2013; Golden et al. 1997; Golden et al. 2008; Faust et al. 2013). While an indirect effect of psychological factors especially in the context of eating disorders is well established, the direct effect of previous and current psychological factors warrants further exploration. Very likely, subtle persisting characteristics of eating behaviours, exercise and energy balance are involved in augmenting the risk for prolonged amenorrhea but remain to be elucidated.

Overall, the time to return of menses seems to depend on the initial cause of FHA with shorter duration till recovery in athletes (Cialdella-Kam et al. 2014) compared to women with eating disorders (Karountzos et al. 2017). The inhomogeneity of studies and the lack of systemic consideration of influencing factors hampers development of good and robust prediction models. 
Comparative studies or reviews on the effect of different treatment strategies to improve chances for

759 return of menses do not exist. Interventions such as increase in weight/ energy availability or adaptation

760 of nutrition have been confirmed to facilitate the return of menstruation, however, specific nutrition

761 concepts have only been investigated in athletes. Stress management is part of the therapeutic approach

762 with eating disorders, but its role to improve chances for return of menses has not been fully explored

763 yet. In addition to the well-known strategies of adequate weight/BMI/percentage body fat, energy

764 balance and psychological well-being, drugs as metreleptin or naltrexone have showed favourable results

765 in some studies but need further investigation.

\section{Open research questions}

More methodologically well-designed studies are needed to close the present gap in our understanding on how the return of menses in FHA can be facilitated. This includes clear definitions and diagnostic criteria of FHA, return of menses, conditions at the beginning of an observation period, interventions and

771 influencing factors/ potential confounders. Further research should address clinically relevant therapeutic 772 targets values for weight, BMI and energy levels as well as overall chances for return of menses. Studies 773 should be prospective, longitudinal and include control groups with medications and other therapeutic 774 interventions tested in a placebo-controlled double-blind design, wherever possible. The pathophysiology 775 of return of menses should also be evaluated in human studies, cover central and peripheral regulatory mechanisms, actual psychological stressors, early stress experiences, as well as genetic and epigenetic 777 factors involved in biological and psychological influences. The latter could serve to identify women at risk 778 for FHA and enable preventive measures.

\section{Practical advice}

781 Clinicians should inform women with FHA on the potential long-term consequences of amenorrhea and 782 the likelihood for return of menses under adequate as well as inadequate conditions. Extensive 783 counselling may be needed in the case of psychopathology or in high performance athletes. As FHA is 
often the combined effect of low weight, excessive exercise, poor nutrition and psychological factors, evaluation of the cause of amenorrhea should always include the exploration of all relevant factors and

786 be carefully differentiated from organic causes of amenorrhea. FHA can persist for several years even 787 after achieving healthy weight/ adequate energy balance and has severe long-term effects if not treated. 788 A such, it is important to aim as early as possible for normal cycle function. Therapeutic support should include adequate nutrition, energy balance, exercise level and mental health. Ideally, support should be provided by an interdisciplinary team of a gynaecologist-obstetrician, a dietitian and a mental health professional. In particular, behavioural changes needed for the improvement of energy balance may necessitate psychotherapeutic support. Non-drug treatment options that eliminate the causes of FHA remain the therapy of choice to regain menstruation. Predicting if and when menses will return is difficult. As the chances for pregnancy strongly rely on women's age (Leeners et al. 2013; Somigliana et al. 2016), medically-assisted reproduction support should be discussed when menses do not reoccur despite adequate nutrition, weight, energy balance and stress management.

\section{Conclusion}

Based on the limited evidence available, the restoration of adequate weight/BMI and energy balance have

800 a clear beneficial effect, but normalization of these factors alone does not reliably result in return of 801 menses. As the physiology of the return of menses and the underlying factors are only poorly understood, 802 it seems unlikely that a precise prediction model for when the menstrual cycle will recover in individual 803 women will be achieved in the near future. Given the severe impact of FHA on womens' overall and 804 reproductive health, there is a clear and urgent need for further research investigating the factors 805 allowing return of menses. Currently, a combination of adequate nutrition, weight, energy balance and 806 stress management still seems to be the most adequate approach to increase chances for the recovery of 807 menses after FHA. 
810 J.P and B.L. contributed to the identification and critical evaluation of the relevant literature, analysis of 811 study results and to drafting the article including the critical discussion of findings. J.P. participated in preparation of the proposal, completed the initial literature research, drafted a first version of the article and participated in finalization of the article. A.H. provided his expertise on central regulatory mechanisms in return of menses, drafted and finalized related passages of the manuscript and critically revised the final version of the manuscript B.L. finalized the concept for the manuscript, supervised the literature research, data extraction and presentation of relevant data. She drafted and finalized different versions of the manuscript and critically revised the final version of the manuscript. All authors approved the final version of this manuscript.

\section{Funding}

821 This study did not receive any specific funding.

\section{Conflicts of interest}

None of the authors has any conflict of interest.

\section{References}

Abbate Daga G, Campisi S, Marzola E, Rocca G, Peris C, Campagnoli C, Peloso A, Vesco S, Rigardetto R, and Fassino S. Amenorrhea in eating disorders: poor stability of symptom after a one-year treatment. Eat Weight Disord 2012: 17; e78-85.

Ackerman KE, Slusarz K, Guereca G, Pierce L, Slattery M, Mendes N, Herzog DB, and Misra M. Higher ghrelin and lower leptin secretion are associated with lower LH secretion in young amenorrheic athletes compared with eumenorrheic athletes and controls. Am J Physiol Endocrinol Metab 2012: 302; E800-806.

Adams MR, Kaplan JR, and Koritnik DR. Psychosocial influences on ovarian endocrine and ovulatory function in Macaca fascicularis. Physiol Behav 1985: 35; 935-940.

Ahima RS, Prabakaran D, Mantzoros C, Qu D, Lowell B, Maratos-Flier E, and Flier JS. Role of leptin in the neuroendocrine response to fasting. Nature 1996: 382; 250-252.

Allsworth JE, Clarke J, Peipert JF, Hebert MR, Cooper A, and Boardman LA. The influence of stress on the menstrual cycle among newly incarcerated women. Women's health issues : official publication of the Jacobs Institute of Women's Health 2007: 17; 202-209. 
American Society for Reproductive Medicine PC. Current evaluation of amenorrhea. Fertil Steril 2008: 90; S219-225.

Andersen AE and Ryan GL. Eating disorders in the obstetric and gynecologic patient population. Obstet Gynecol 2009: 114; 1353-1367.

Andrico S, Gambera A, Specchia C, Pellegrini C, Falsetti L, and Sartori E. Leptin in functional hypothalamic amenorrhoea. Hum Reprod 2002: 17; 2043-2048.

Anselmo-Franci JA, Franci CR, Krulich L, Antunes-Rodrigues J, and McCann SM. Locus coeruleus lesions decrease norepinephrine input into the medial preoptic area and medial basal hypothalamus and block the LH, FSH and prolactin preovulatory surge. Brain Res 1997: 767; 289-296.

Arends JC, Cheung MY, Barrack MT, and Nattiv A. Restoration of menses with nonpharmacologic therapy in college athletes with menstrual disturbances: a 5-year retrospective study. Int J Sport Nutr Exerc Metab 2012: 22; 98-108.

Arimura C, Nozaki T, Takakura S, Kawai K, Takii M, Sudo N, and Kubo C. Predictors of menstrual resumption by patients with anorexia nervosa. Eat Weight Disord 2010: 15; e226-233.

Armario A, Marti O, Molina T, de Pablo J, and Valdes M. Acute stress markers in humans: response of plasma glucose, cortisol and prolactin to two examinations differing in the anxiety they provoke. Psychoneuroendocrinology 1996: 21; 17-24.

Armeanu MC, Berkhout GM, and Schoemaker J. Pulsatile luteinizing hormone secretion in hypothalamic amenorrhea, anorexia nervosa, and polycystic ovarian disease during naltrexone treatment. Fertil Steril 1992: 57; 762-770.

Audi L, Mantzoros CS, Vidal-Puig A, Vargas D, Gussinye M, and Carrascosa A. Leptin in relation to resumption of menses in women with anorexia nervosa. Mol Psychiatry 1998: 3; 544547.

Barakat R, Oakley O, Kim H, Jin J, and Ko CJ. Extra-gonadal sites of estrogen biosynthesis and function. BMB Rep 2016: 49; 488-496.

Barnhart KT and Schreiber CA. Return to fertility following discontinuation of oral contraceptives. Fertil Steril 2009: 91; 659-663.

Beaglehole B, Mulder RT, Frampton CM, Boden JM, Newton-Howes G, and Bell CJ. Psychological distress and psychiatric disorder after natural disasters: systematic review and metaanalysis. Br J Psychiatry 2018: 213; 716-722.

Benson JE, Engelbert-Fenton KA, and Eisenman PA. Nutritional aspects of amenorrhea in the female athlete triad. Int J Sport Nutr 1996: 6; 134-145.

Berga S and Naftolin F. Neuroendocrine control of ovulation. Gynecol Endocrinol 2012: 28 Suppl 1; 9-13.

Berga SL. Behaviorally induced reproductive compromise in women and men. Semin Reprod Endocrinol 1997: 15; 47-53.

Berga SL. Stress and reprodution: a tale of false dichotomy? Endocrinology 2008: 149; 867-868.

Berga SL, Daniels TL, and Giles DE. Women with functional hypothalamic amenorrhea but not other forms of anovulation display amplified cortisol concentrations. Fertil Steril 1997: 67; 1024-1030.

Berga SL and Girton LG. The psychoneuroendocrinology of functional hypothalamic amenorrhea. Psychiatr Clin North Am 1989: 12; 105-116.

Berga SL and Loucks TL. Use of cognitive behavior therapy for functional hypothalamic amenorrhea. Ann N Y Acad Sci 2006: 1092; 114-129. 
Berga SL, Marcus MD, Loucks TL, Hlastala S, Ringham R, and Krohn MA. Recovery of ovarian activity in women with functional hypothalamic amenorrhea who were treated with cognitive behavior therapy. Fertil Steril 2003: 80; 976-981.

Berkman ND, Bulik CM, Brownley KA, Lohr KN, Sedway JA, Rooks A, and Gartlehner G. Management of eating disorders. Evid Rep Technol Assess (Full Rep) 2006; 1-166.

Berner LA, Feig EH, Witt AA, and Lowe MR. Menstrual cycle loss and resumption among patients with anorexia nervosa spectrum eating disorders: Is relative or absolute weight more influential? Int J Eat Disord 2017: 50; 442-446.

Bethea CL, Centeno ML, and Cameron JL. Neurobiology of stress-induced reproductive dysfunction in female macaques. Molecular neurobiology 2008: 38; 199-230.

Bethea CL, Lu NZ, Gundlah C, and Streicher JM. Diverse actions of ovarian steroids in the serotonin neural system. Front Neuroendocrinol 2002: 23; 41-100.

Bethea CL, Pau FKY, Fox S, Hess DL, Berga SL, and Cameron JL. Sensitivity to stress-induced reproductive dysfunction linked to activity of the serotonin system. Fertility and Sterility 2005: 83; 148-155.

Bodell LP and Mayer LES. Percent body fat is a risk factor for relapse in anorexia nervosa: a replication study. Int J Eat Disord 2011: 44; 118-123.

Bomba M, Gambera A, Bonini L, Peroni M, Neri F, Scagliola P, and Nacinovich R. Endocrine profiles and neuropsychologic correlates of functional hypothalamic amenorrhea in adolescents. Fertil Steril 2007: 87; 876-885.

Brambilla F, Monteleone P, Bortolotti F, Dalle Grave R, Todisco P, Favaro A, Santonastaso P, Ramacciotti C, Paoli R, and Maj M. Persistent amenorrhoea in weight-recovered anorexics: psychological and biological aspects. Psychiatry Research 2003: 118; 249-257.

Breen KM, Davis TL, Doro LC, Nett TM, Oakley AE, Padmanabhan V, Rispoli LA, Wagenmaker ER, and Karsch FJ. Insight into the neuroendocrine site and cellular mechanism by which cortisol suppresses pituitary responsiveness to gonadotropin-releasing hormone. Endocrinology 2008: 149; 767-773.

Brothers KJ, Wu S, DiVall SA, Messmer MR, Kahn CR, Miller RS, Radovick S, Wondisford FE, and Wolfe $A$. Rescue of obesity-induced infertility in female mice due to a pituitary-specific knockout of the insulin receptor. Cell Metab 2010: 12; 295-305.

Brown E, Bain J, Lerner P, and Shaul D. Psychological, hormonal, and weight disturbances in functional amenorrhea. Can J Psychiatry 1983: 28; 624-628.

Brundu B, Loucks TL, Adler L, Cameron JL, and Berga SL. Increased cortisol in the cerebrospinal fluid of women with functional hypothalamic amenorrhea. J Clin Endocrinol Metab 2006: 91; 1561-1565.

Bruning JC, Gautam D, Burks DJ, Gillette J, Schubert M, Orban PC, Klein R, Krone W, MullerWieland $D$, and Kahn CR. Role of brain insulin receptor in control of body weight and reproduction. Science 2000: 289; 2122-2125.

Buck GM, Sever LE, Batt RE, and Mendola P. Life-style factors and female infertility. Epidemiology 1997: 8; 435-441.

Bullen BA, Skrinar GS, Beitins IZ, von Mering G, Turnbull BA, and McArthur JW. Induction of menstrual disorders by strenuous exercise in untrained women. N Engl J Med 1985: 312; 1349-1353.

Cameron JL. Regulation of reproductive hormone secretion in primates by short-term changes in nutrition. Rev Reprod 1996: 1; 117-126. 
Caronia LM, Martin C, Welt CK, Sykiotis GP, Quinton R, Thambundit A, Avbelj M, Dhruvakumar $\mathrm{S}$, Plummer $\mathrm{L}$, Hughes VA, et al. A genetic basis for functional hypothalamic amenorrhea. N Engl J Med 2011: 364; 215-225.

Caspi A, Hariri AR, Holmes A, Uher R, and Moffitt TE. Genetic sensitivity to the environment: the case of the serotonin transporter gene and its implications for studying complex diseases and traits. Am J Psychiatry 2010: 167; 509-527.

Caspi A, Sugden K, Moffitt TE, Taylor A, Craig IW, Harrington H, McClay J, Mill J, Martin J, Braithwaite $A$, et al. Influence of life stress on depression: moderation by a polymorphism in the 5-HTT gene. Science 2003: 301; 386-389.

Castellano JM and Tena-Sempere M. Metabolic control of female puberty: potential therapeutic targets. Expert Opin Ther Targets 2016: 20; 1181-1193.

Cejtin HE, Evans CT, Greenblatt R, Minkoff H, Weber KM, Wright R, Colie C, Golub E, and Massad LS. Prolonged Amenorrhea and Resumption of Menses in Women with HIV. J Womens Health (Larchmt) 2018.

Chand D and Lovejoy DA. Stress and reproduction: controversies and challenges. Gen Comp Endocrinol 2011: 171; 253-257.

Chianese R, Colledge WH, Fasano S, and Meccariello R. Editorial: The Multiple Facets of Kisspeptin Activity in Biological Systems. Front Endocrinol (Lausanne) 2018: 9; 727.

Chou SH, Chamberland JP, Liu X, Matarese G, Gao C, Stefanakis R, Brinkoetter MT, Gong H, Arampatzi $\mathrm{K}$, and Mantzoros CS. Leptin is an effective treatment for hypothalamic amenorrhea. Proc Natl Acad Sci U S A 2011: 108; 6585-6590.

Christo K, Cord J, Mendes N, Miller KK, Goldstein MA, Klibanski A, and Misra M. Acylated ghrelin and leptin in adolescent athletes with amenorrhea, eumenorrheic athletes and controls: a cross-sectional study. Clin Endocrinol (Oxf) 2008: 69; 628-633.

Cialdella-Kam L, Guebels CP, Maddalozzo GF, and Manore MM. Dietary intervention restored menses in female athletes with exercise-associated menstrual dysfunction with limited impact on bone and muscle health. Nutrients 2014: 6; 3018-3039.

Collaborative Group HFiBC. Type and timing of menopausal hormone therapy and breast cancer risk: individual participant meta-analysis of the worldwide epidemiological evidence. Lancet 2019: 394; 1159-1168.

Cominato L, da Silva MM, Steinmetz L, Pinzon V, Fleitlich-Bilyk B, and Damiani D. Menstrual cycle recovery in patients with anorexia nervosa: the importance of insulin-like growth factor 1. Horm Res Paediatr 2014: 82; 319-323.

Craig J, Zhu H, Dyce PW, Petrik J, and Li J. Leptin enhances oocyte nuclear and cytoplasmic maturation via the mitogen-activated protein kinase pathway. Endocrinology 2004: 145; 5355-5363.

Dan-Goor M, Sasson S, Davarashvili A, and Almagor M. Expression of glucose transporter and glucose uptake in human oocytes and preimplantation embryos. Hum Reprod 1997: 12; 2508-2510.

Davis AR, Kroll R, Soltes B, Zhang N, Grubb GS, and Constantine GD. Occurrence of menses or pregnancy after cessation of a continuous oral contraceptive. Fertil Steril 2008: 89; 1059-1063.

Davis $C$ and Claridge $\mathrm{G}$. The eating disorders as addiction: a psychobiological perspective. Addict Behav 1998: 23; 463-475.

De Souza MJ, Leidy HJ, O'Donnell E, Lasley B, and Williams NI. Fasting ghrelin levels in physically active women: relationship with menstrual disturbances and metabolic hormones. $J$ Clin Endocrinol Metab 2004: 89; 3536-3542. 
Dei M, Seravalli V, Bruni V, Balzi D, and Pasqua A. Predictors of recovery of ovarian function after weight gain in subjects with amenorrhea related to restrictive eating disorders. Gynecol Endocrinol 2008: 24; 459-464.

Dempfle A, Herpertz-Dahlmann B, Timmesfeld N, Schwarte R, Egberts KM, Pfeiffer E, Fleischhaker $C$, Wewetzer $C$, and Buhren K. Predictors of the resumption of menses in adolescent anorexia nervosa. BMC Psychiatry 2013: 13; 308.

Divall SA, Williams TR, Carver SE, Koch L, Bruning JC, Kahn CR, Wondisford F, Radovick S, and Wolfe A. Divergent roles of growth factors in the GnRH regulation of puberty in mice. J Clin Invest 2010: 120; 2900-2909.

Dobson H, Ghuman S, Prabhakar S, and Smith R. A conceptual model of the influence of stress on female reproduction. Reproduction 2003: 125; 151-163.

Dominko T and First NL. Timing of meiotic progression in bovine oocytes and its effect on early embryo development. Mol Reprod Dev 1997: 47; 456-467.

Donato J, Jr., Cravo RM, Frazao R, Gautron L, Scott MM, Lachey J, Castro IA, Margatho LO, Lee S, Lee $C$, et al. Leptin's effect on puberty in mice is relayed by the ventral premammillary nucleus and does not require signaling in Kiss1 neurons. J Clin Invest 2011: 121; 355368.

Drew FL. The epidemiology of secondary amenorrhea. J Chronic Dis 1961: 14; 396-407.

Dudas B and Merchenthaler I. Close juxtapositions between luteinizing hormone-releasing hormone-immunoreactive neurons and corticotropin-releasing factor-immunoreactive axons in the human diencephalon. J Clin Endocrinol Metab 2002: 87; 5778-5784.

Dueck CA, Matt KS, Manore MM, and Skinner JS. Treatment of athletic amenorrhea with a diet and training intervention program. Int I Sport Nutr 1996: 6; 24-40.

Dvornyk $\mathrm{V}$ and Waqar ul H. Genetics of age at menarche: a systematic review. Hum Reprod Update 2012: 18; 198-210.

El Ghoch M, Alberti M, Milanese C, Battistini NC, Pellegrini M, Capelli C, Calugi S, and Dalle Grave R. Comparison between dual-energy X-ray absorptiometry and skinfolds thickness in assessing body fat in anorexia nervosa before and after weight restoration. Clin Nutr 2012: 31; 911-916.

El Ghoch M, Calugi S, Chignola E, Bazzani PV, and Dalle Grave R. Body fat and menstrual resumption in adult females with anorexia nervosa: a 1-year longitudinal study. J Hum Nutr Diet 2016: 29; 662-666.

Elliott-Sale KJ, Tenforde AS, Parziale AL, Holtzman B, and Ackerman KE. Endocrine Effects of Relative Energy Deficiency in Sport. Int J Sport Nutr Exerc Metab 2018: 28; 335-349.

Evans MC and Anderson GM. Neuroendocrine integration of nutritional signals on reproduction. J Mol Endocrinol 2017: 58; R107-r128.

Facchinetti F, Fava M, Fioroni L, Genazzani AD, and Genazzani AR. Stressful life events and affective disorders inhibit pulsatile LH secretion in hypothalamic amenorrhea. Psychoneuroendocrinology 1993: 18; 397-404.

Falsetti L, Gambera A, Barbetti L, and Specchia C. Long-term follow-up of functional hypothalamic amenorrhea and prognostic factors. J Clin Endocrinol Metab 2002: 87; 500-505.

Faust JP, Goldschmidt AB, Anderson KE, Glunz C, Brown M, Loeb KL, Katzman DK, and Le Grange D. Resumption of menses in anorexia nervosa during a course of family-based treatment. J Eat Disord 2013: 1; 12. 
Fava GA, Trombini G, Grandi S, Bernardi M, Evangelisti LP, Santarsiero G, and Orlandi C. Depression and anxiety associated with secondary amenorrhea. Psychosomatics 1984: 25; 905-908.

Favaro A and Santonastaso P. Seasonality and the prediction of weight at resumption of menses in anorexia nervosa. Fertil Steril 2009: 91; 1395-1397.

Fernandez-Fernandez R, Martini AC, Navarro VM, Castellano JM, Dieguez C, Aguilar E, Pinilla L, and Tena-Sempere M. Novel signals for the integration of energy balance and reproduction. Mol Cell Endocrinol 2006: 254-255; 127-132.

Filova B, Malinova M, Babickova J, Tothova L, Ostatnikova D, Celec P, and Hodosy J. Effects of testosterone and estradiol on anxiety and depressive-like behavior via a non-genomic pathway. Neurosci Bull 2015: 31; 288-296.

Fioroni L, Fava M, Genazzani AD, Facchinetti F, and Genazzani AR. Life events impact in patients with secondary amenorrhoea. J Psychosom Res 1994: 38; 617-622.

Flier JS. Clinical review 94: What's in a name? In search of leptin's physiologic role. J Clin Endocrinol Metab 1998: 83; 1407-1413.

Flinn MV, Nepomnaschy PA, Muehlenbein MP, and Ponzi D. Evolutionary functions of early social modulation of hypothalamic-pituitary-adrenal axis development in humans. Neurosci Biobehav Rev 2011: 35; 1611-1629.

Freimuth M, Moniz S, and Kim SR. Clarifying exercise addiction: differential diagnosis, cooccurring disorders, and phases of addiction. Int J Environ Res Public Health 2011: 8; 4069-4081.

Fries H, Nillius SJ, and Pettersson F. Epidemiology of secondary amenorrhea. II. A retrospective evaluation of etiology with special regard to psychogenic factors and weight loss. Am J Obstet Gynecol 1974: 118; 473-479.

Frisancho AR. New standards of weight and body composition by frame size and height for assessment of nutritional status of adults and the elderly. Am J Clin Nutr 1984: 40; 808819.

Frisch RE. Body fat, menarche, fitness and fertility. Hum Reprod 1987: 2; 521-533.

Frisch RE and McArthur JW. Menstrual cycles: fatness as a determinant of minimum weight for height necessary for their maintenance or onset. Science 1974: 185; 949-951.

Gadpaille WJ, Sanborn CF, and Wagner WW, Jr. Athletic amenorrhea, major affective disorders, and eating disorders. Am J Psychiatry 1987: 144; 939-942.

Gagnier JJ, Kienle G, Altman DG, Moher D, Sox H, and Riley D. The CARE Guidelines: Consensusbased Clinical Case Reporting Guideline Development. Glob Adv Health Med 2013: 2; 3843.

Garcia-Garcia RM. Integrative control of energy balance and reproduction in females. ISRN Vet Sci 2012: 2012; 121389.

Gaytan F, Barreiro ML, Chopin LK, Herington AC, Morales C, Pinilla L, Casanueva FF, Aguilar E, Dieguez $\mathrm{C}$, and Tena-Sempere M. Immunolocalization of ghrelin and its functional receptor, the type 1a growth hormone secretagogue receptor, in the cyclic human ovary. J Clin Endocrinol Metab 2003: 88; 879-887.

Gaytan F, Morales C, Barreiro ML, Jeffery P, Chopin LK, Herington AC, Casanueva FF, Aguilar E, Dieguez $C$, and Tena-Sempere $M$. Expression of growth hormone secretagogue receptor type 1a, the functional ghrelin receptor, in human ovarian surface epithelium, mullerian duct derivatives, and ovarian tumors. J Clin Endocrinol Metab 2005: 90; 1798-1804. 
Genazzani AD, Chierchia E, Santagni S, Rattighieri E, Farinetti A, and Lanzoni C. Hypothalamic amenorrhea: from diagnosis to therapeutical approach. Ann Endocrinol (Paris) 2010: 71; 163-169.

Genazzani AD, Meczekalski B, Podfigurna-Stopa A, Santagni S, Rattighieri E, Ricchieri F, Chierchia $E$, and Simoncini T. Estriol administration modulates luteinizing hormone secretion in women with functional hypothalamic amenorrhea. Fertil Steril 2012: 97; 483-488.

Genazzani AD, Petraglia F, Gastaldi M, Volpogni C, Gamba O, and Genazzani AR. Naltrexone treatment restores menstrual cycles in patients with weight loss-related amenorrhea. Fertil Steril 1995: 64; 951-956.

Genazzani AD, Petraglia F, Gastaldi M, Volpogni C, Gamba O, and Genazzani AR. Naltrexone treatment restores menstrual cycles in patients with weight loss-related amenorrhea*. Fertility and Sterility 1995: 64; 951-956.

Giles DE and Berga SL. Cognitive and psychiatric correlates of functional hypothalamic amenorrhea: a controlled comparison. Fertil Steril 1993: 60; 486-492.

Godwin CL, Wohl DA, Fischer Nd WA, Singh K, Hawks DA, Devore EE, and Brown J. Reproductive health sequelae among women who survived Ebola virus disease in Liberia. Int $J$ Gynaecol Obstet 2019: 146; 212-217.

Golden NH, Jacobson MS, Schebendach J, Solanto MV, Hertz SM, and Shenker IR. Resumption of menses in anorexia nervosa. Arch Pediatr Adolesc Med 1997: 151; 16-21.

Golden NH, Jacobson MS, Sterling WM, and Hertz S. Treatment goal weight in adolescents with anorexia nervosa: use of BMI percentiles. Int J Eat Disord 2008: 41; 301-306.

Gordley LB, Lemasters G, Simpson SR, and Yiin JH. Menstrual disorders and occupational, stress, and racial factors among military personnel. J Occup Environ Med 2000: 42; 871-881.

Gordon CM. Clinical practice. Functional hypothalamic amenorrhea. N Engl J Med 2010: 363; 365-371.

Gordon CM, Ackerman KE, Berga SL, Kaplan JR, Mastorakos G, Misra M, Murad MH, Santoro NF, and Warren MP. Functional Hypothalamic Amenorrhea: An Endocrine Society Clinical Practice Guideline. J Clin Endocrinol Metab 2017: 102; 1413-1439.

Goyal M, Singh S, Sibinga EMS, Gould NF, Rowland-Seymour A, Sharma R, Berger Z, Sleicher D, Maron DD, Shihab HM, et al. Meditation Programs for Psychological Stress and Wellbeing: A Systematic Review and Meta-analysis. JAMA Internal Medicine 2014: 174; 357368.

Grabe HJ, Lange M, Wolff B, Volzke H, Lucht M, Freyberger HJ, John U, and Cascorbi I. Mental and physical distress is modulated by a polymorphism in the 5-HT transporter gene interacting with social stressors and chronic disease burden. Mol Psychiatry 2005: 10; 220-224.

Grinspoon SK, Askari H, Landt ML, Nathan DM, Schoenfeld DA, Hayden DL, Laposata M, Hubbard J, and Klibanski A. Effects of fasting and glucose infusion on basal and overnight leptin concentrations in normal-weight women. Am J Clin Nutr 1997: 66; 1352-1356.

Grodstein F, Goldman MB, and Cramer DW. Infertility in women and moderate alcohol use. Am J Public Health 1994: 84; 1429-1432.

Hall A, Ofei-Tenkorang NA, Machan JT, and Gordon CM. Use of yoga in outpatient eating disorder treatment: a pilot study. J Eat Disord 2016: 4; 38.

Han S-K and Herbison AE. Norepinephrine Suppresses Gonadotropin-Releasing Hormone Neuron Excitability in the Adult Mouse. Endocrinology 2008: 149; 1129-1135. 
1117

1118

1119

1120

1121

1122

1123

1124

1125

1126

1127

1128

1129

1130

1131

1132

1133

1134

1135

1136

1137

1138

1139

1140

1141

1142

1143

1144

1145

1146

1147

1148

1149

1150

1151

1152

1153

1154

1155

1156

1157

1158

1159

1160

1161

1162

1163

Harlow SD and Matanoski GM. The association between weight, physical activity, and stress and variation in the length of the menstrual cycle. Am J Epidemiol 1991: 133; 38-49. Herbison AE. Noradrenergic regulation of cyclic GnRH secretion. Rev Reprod 1997: 2; 1-6. Herbison AE. Control of puberty onset and fertility by gonadotropin-releasing hormone neurons. Nat Rev Endocrinol 2016: 12; 452-466.

Herbison AE. The Gonadotropin-Releasing Hormone Pulse Generator. Endocrinology 2018: 159; 3723-3736.

Hessler S, Liu X, and Herbison AE. Direct inhibition of arcuate kisspeptin neurones by neuropeptide $Y$ in the male and female mouse. J Neuroendocrinol 2020: 32; e12849.

Hilton LK and Loucks AB. Low energy availability, not exercise stress, suppresses the diurnal rhythm of leptin in healthy young women. Am J Physiol Endocrinol Metab 2000: 278; E43-49.

Holtkamp K, Mika C, Grzella I, Heer M, Pak H, Hebebrand J, and Herpertz-Dahlmann B. Reproductive function during weight gain in anorexia nervosa. Leptin represents a metabolic gate to gonadotropin secretion. J Neural Transm (Vienna) 2003: 110; 427-435.

Holtzman B and Ackerman KE. Measurement, Determinants, and Implications of Energy Intake in Athletes. Nutrients 2019: 11.

Howe G, Westhoff C, Vessey M, and Yeates D. Effects of age, cigarette smoking, and other factors on fertility: findings in a large prospective study. Br Med J (Clin Res Ed) 1985: 290; 1697-1700.

Iorga A, Cunningham CM, Moazeni S, Ruffenach G, Umar S, and Eghbali M. The protective role of estrogen and estrogen receptors in cardiovascular disease and the controversial use of estrogen therapy. Biol Sex Differ 2017: 8; 33.

Jacoangeli F, Masala S, Staar Mezzasalma F, Fiori R, Martinetti A, Ficoneri C, Novi B, Pierangeli S, Marchetti G, Simonetti G, et al. Amenorrhea after weight recover in anorexia nervosa: role of body composition and endocrine abnormalities. Eat Weight Disord 2006: 11; e20-26.

Jacobs HS, Knuth UA, Hull MG, and Franks S. Post-"pill" amenorrhoea--cause or coincidence? $\mathrm{Br}$ Med J 1977: 2; 940-942.

Jacobs MB, Boynton-Jarrett RD, and Harville EW. Adverse childhood event experiences, fertility difficulties and menstrual cycle characteristics. J Psychosom Obstet Gynaecol 2015: 36; 46-57.

Jimerson DC, Mantzoros C, Wolfe BE, and Metzger ED. Decreased serum leptin in bulimia nervosa. J Clin Endocrinol Metab 2000: 85; 4511-4514.

Joffe H, Kim DR, Foris JM, Baldassano CF, Gyulai L, Hwang CH, McLaughlin WL, Sachs GS, Thase $\mathrm{ME}$, Harlow BL, et al. Menstrual dysfunction prior to onset of psychiatric illness is reported more commonly by women with bipolar disorder than by women with unipolar depression and healthy controls. J Clin Psychiatry 2006: 67; 297-304.

Johnson J and Whitaker AH. Adolescent smoking, weight changes, and binge-purge behavior: associations with secondary amenorrhea. Am J Public Health 1992: 82; 47-54.

Karountzos V, Lambrinoudaki I, Tsitsika A, and Deligeoroglou E. The role of total body fat mass and trunk fat mass, combined with other endocrine factors, in menstrual recovery and psychopathology of adolescents with Anorexia Nervosa. Gynecol Endocrinol 2017: 33; 757-762.

Katterman SN, Kleinman BM, Hood MM, Nackers LM, and Corsica JA. Mindfulness meditation as an intervention for binge eating, emotional eating, and weight loss: a systematic review. Eat Behav 2014: 15; 197-204. 
Katz P, Showstack J, Smith JF, Nachtigall RD, Millstein SG, Wing H, Eisenberg ML, Pasch LA, Croughan MS, and Adler N. Costs of infertility treatment: results from an 18-month prospective cohort study. Fertil Steril 2011: 95; 915-921.

Keski-Rahkonen A and Mustelin L. Epidemiology of eating disorders in Europe: prevalence, incidence, comorbidity, course, consequences, and risk factors. Curr Opin Psychiatry 2016: 29; 340-345.

Khoury SA, Reame NE, Kelch RP, and Marshall JC. Diurnal patterns of pulsatile luteinizing hormone secretion in hypothalamic amenorrhea: reproducibility and responses to opiate blockade and an alpha 2-adrenergic agonist. J Clin Endocrinol Metab 1987: 64; 755-762.

Kluge M, Schussler P, Schmidt D, Uhr M, and Steiger A. Ghrelin suppresses secretion of luteinizing hormone (LH) and follicle-stimulating hormone (FSH) in women. J Clin Endocrinol Metab 2012: 97; E448-451.

Kohmura $\mathrm{H}$, Miyake A, Aono $\mathrm{T}$, and Tanizawa O. Recovery of reproductive function in patients with anorexia nervosa: a 10-year follow-up study. Eur J Obstet Gynecol Reprod Biol 1986: 22; 293-296.

Kondoh Y, Uemura T, Murase M, Yokoi N, Ishikawa M, and Hirahara F. A longitudinal study of disturbances of the hypothalamic-pituitary-adrenal axis in women with progestinnegative functional hypothalamic amenorrhea. Fertil Steril 2001: 76; 748-752.

Kopp-Woodroffe SA, Manore MM, Dueck CA, Skinner JS, and Matt KS. Energy and nutrient status of amenorrheic athletes participating in a diet and exercise training intervention program. Int J Sport Nutr 1999: 9; 70-88.

Kopp W, Blum WF, von Prittwitz S, Ziegler A, Lubbert H, Emons G, Herzog W, Herpertz S, Deter $\mathrm{HC}$, Remschmidt $\mathrm{H}$, et al. Low leptin levels predict amenorrhea in underweight and eating disordered females. Mol Psychiatry 1997: 2; 335-340.

Kuczmarski RJ, Ogden CL, Grummer-Strawn LM, Flegal KM, Guo SS, Wei R, Mei Z, Curtin LR, Roche AF, and Johnson CL. CDC growth charts: United States. Adv Data 2000; 1-27.

Lado-Abeal J, Clapper JA, Chen Zhu B, Hough CM, Syapin PJ, and Norman RL. Hypoglycemiainduced suppression of luteinizing hormone (LH) secretion in intact female rhesus macaques: role of vasopressin and endogenous opioids. Stress 2002: 5; 113-119.

Lagowska K, Kapczuk K, Friebe Z, and Bajerska J. Effects of dietary intervention in young female athletes with menstrual disorders. J Int Soc Sports Nutr 2014: 11; 21.

Lateef OM and Akintubosun MO. Sleep and Reproductive Health. Journal of circadian rhythms 2020: 18; 1 -1.

Laughlin GA, Dominguez CE, and Yen SS. Nutritional and endocrine-metabolic aberrations in women with functional hypothalamic amenorrhea. J Clin Endocrinol Metab 1998: 83; 25-32.

Laughlin GA and Yen SS. Nutritional and endocrine-metabolic aberrations in amenorrheic athletes. J Clin Endocrinol Metab 1996: 81; 4301-4309.

Lawson EA, Donoho D, Miller KK, Misra M, Meenaghan E, Lydecker J, Wexler T, Herzog DB, and Klibanski A. Hypercortisolemia is associated with severity of bone loss and depression in hypothalamic amenorrhea and anorexia nervosa. J Clin Endocrinol Metab 2009: 94; 4710-4716.

Le Grange D, Doyle PM, Swanson SA, Ludwig K, Glunz C, and Kreipe RE. Calculation of expected body weight in adolescents with eating disorders. Pediatrics 2012: 129; e438-446.

Leeners B, Geary N, Tobler PN, and Asarian L. Ovarian hormones and obesity. Hum Reprod Update 2017: 23; 300-321. 
Leeners B, Geraedts K, Imthurn B, and Stiller R. The relevance of age in female human reproduction--current situation in Switzerland and pathophysiological background from a comparative perspective. Gen Comp Endocrinol 2013: 188; 166-174.

Leeners B, Stiller R, Block E, Gorres G, Imthurn B, and Rath W. Effect of childhood sexual abuse on gynecologic care as an adult. Psychosomatics 2007: 48; 385-393.

Levin VA, Jiang X, and Kagan R. Estrogen therapy for osteoporosis in the modern era. Osteoporos Int 2018: 29; 1049-1055.

Li XF and O'Byrne. Stress and the reproductive system. Knobil and Neill's Physiology of Reproduction 2015: 2; 1637-1660.

Liberati A, Altman DG, Tetzlaff J, Mulrow C, Gotzsche PC, loannidis JP, Clarke M, Devereaux PJ, Kleijnen J, and Moher D. The PRISMA statement for reporting systematic reviews and meta-analyses of studies that evaluate health care interventions: explanation and elaboration. J Clin Epidemiol 2009: 62; e1-34.

Lieberman JL, MJ DES, Wagstaff DA, and Williams NI. Menstrual Disruption with Exercise Is Not Linked to an Energy Availability Threshold. Med Sci Sports Exerc 2018: 50; 551-561.

Lima FB, Centeno ML, Costa ME, Reddy AP, Cameron JL, and Bethea CL. Stress sensitive female macaques have decreased fifth Ewing variant (Fev) and serotonin-related gene expression that is not reversed by citalopram. Neuroscience 2009: 164; 676-691.

Loucks AB, Kiens B, and Wright HH. Energy availability in athletes. J Sports Sci 2011: 29 Suppl 1; S7-15.

Loucks AB, Mortola JF, Girton L, and Yen SS. Alterations in the hypothalamic-pituitary-ovarian and the hypothalamic-pituitary-adrenal axes in athletic women. $J$ Clin Endocrinol Metab 1989: 68; 402-411.

Loucks $A B$ and Thuma JR. Luteinizing hormone pulsatility is disrupted at a threshold of energy availability in regularly menstruating women. J Clin Endocrinol Metab 2003: 88; 297-311.

Loucks $A B$, Verdun $M$, and Heath EM. Low energy availability, not stress of exercise, alters LH pulsatility in exercising women. J Appl Physiol (1985) 1998: 84; 37-46.

Magliano DJ, Rogers SL, Abramson MJ, and Tonkin AM. Hormone therapy and cardiovascular disease: a systematic review and meta-analysis. Bjog 2006: 113; 5-14.

Mallinson RJ, Williams NI, Olmsted MP, Scheid JL, Riddle ES, and De Souza MJ. A case report of recovery of menstrual function following a nutritional intervention in two exercising women with amenorrhea of varying duration. J Int Soc Sports Nutr 2013: 10; 34.

Manonai J, Chittacharoen A, and Theppisai U. Effect of estradiol valerate and levonorgestrel on vaginal health. Eur J Obstet Gynecol Reprod Biol 2004: 115; 190-193.

Manore MM, Kam LC, and Loucks AB. The female athlete triad: components, nutrition issues, and health consequences. J Sports Sci 2007: 25 Suppl 1; S61-71.

Mantzoros C, Flier JS, Lesem MD, Brewerton TD, and Jimerson DC. Cerebrospinal fluid leptin in anorexia nervosa: correlation with nutritional status and potential role in resistance to weight gain. J Clin Endocrinol Metab 1997: 82; 1845-1851.

Marcus MD, Loucks TL, and Berga SL. Psychological correlates of functional hypothalamic amenorrhea. Fertil Steril 2001: 76; 310-316.

Marjoribanks J, Farquhar C, Roberts $\mathrm{H}$, Lethaby A, and Lee J. Long-term hormone therapy for perimenopausal and postmenopausal women. Cochrane Database Syst Rev 2017: 1; Cd004143.

Martini MG, Solmi F, Krug I, Karwautz A, Wagner G, Fernandez-Aranda F, Treasure J, and Micali $\mathrm{N}$. Associations between eating disorder diagnoses, behaviors, and menstrual dysfunction in a clinical sample. Arch Womens Ment Health 2016: 19; 553-557. 
Mastorakos G, Pavlatou MG, and Mizamtsidi M. The hypothalamic-pituitary-adrenal and the hypothalamic- pituitary-gonadal axes interplay. Pediatr Endocrinol Rev 2006: 3 Suppl 1; 172-181.

Mayer LE, Klein DA, Black E, Attia E, Shen W, Mao X, Shungu DC, Punyanita M, Gallagher D, Wang J, et al. Adipose tissue distribution after weight restoration and weight maintenance in women with anorexia nervosa. Am J Clin Nutr 2009: 90; 1132-1137.

McCosh RB, Breen KM, and Kauffman AS. Neural and endocrine mechanisms underlying stressinduced suppression of pulsatile LH secretion. Mol Cell Endocrinol 2019: 498; 110579.

Mecklenburg RS, Loriaux DL, Thompson RH, Andersen AE, and Lipsett MB. Hypothalamic dysfunction in patients with anorexia nervosa. Medicine (Baltimore) 1974: 53; 147-159.

Meczekalski B, Podfigurna-Stopa A, Warenik-Szymankiewicz A, and Genazzani AR. Functional hypothalamic amenorrhea: current view on neuroendocrine aberrations. Gynecol Endocrinol 2008: 24; 4-11.

Melin A, Tornberg AB, Skouby S, Moller SS, Faber J, Sundgot-Borgen J, and Sjodin A. Low-energy density and high fiber intake are dietary concerns in female endurance athletes. Scand $J$ Med Sci Sports 2016: 26; 1060-1071.

Mello NK. Effects of alcohol abuse on reproductive function in women. Recent Dev Alcohol 1988: 6; 253-276.

Mendelson T. Stress, Emotional. In Gellman, MD and Turner, JR (eds) Encyclopedia of Behavioral Medicine. 2013. Springer New York, New York, NY, pp 1906-1908.

Michopoulos V, Berga SL, Kaplan JR, and Wilson ME. Social subordination and polymorphisms in the gene encoding the serotonin transporter enhance estradiol inhibition of luteinizing hormone secretion in female rhesus monkeys. Biol Reprod 2009: 81; 1154-1163.

Michopoulos V, Mancini F, Loucks TL, and Berga SL. Neuroendocrine recovery initiated by cognitive behavioral therapy in women with functional hypothalamic amenorrhea: a randomized, controlled trial. Fertil Steril 2013: 99; 2084-2091.e2081.

Miller KK, Grinspoon S, Gleysteen S, Grieco KA, Ciampa J, Breu J, Herzog DB, and Klibanski A. Preservation of neuroendocrine control of reproductive function despite severe undernutrition. J Clin Endocrinol Metab 2004: 89; 4434-4438.

Miller KK, Parulekar MS, Schoenfeld E, Anderson E, Hubbard J, Klibanski A, and Grinspoon SK. Decreased leptin levels in normal weight women with hypothalamic amenorrhea: the effects of body composition and nutritional intake. J Clin Endocrinol Metab 1998: 83; 2309-2312.

Misra M, Prabhakaran R, Miller KK, Tsai P, Lin A, Lee N, Herzog DB, and Klibanski A. Role of cortisol in menstrual recovery in adolescent girls with anorexia nervosa. Pediatr Res 2006: 59; 598-603.

Mountjoy M, Sundgot-Borgen JK, Burke LM, Ackerman KE, Blauwet C, Constantini N, Lebrun C, Lundy $B$, Melin AK, Meyer NL, et al. IOC consensus statement on relative energy deficiency in sport (RED-S): 2018 update. Br J Sports Med 2018: 52; 687.

Murahashi K, Bucholtz DC, Nagatani S, Tsukahara S, Tsukamura H, Foster DL, and Maeda KI. Suppression of luteinizing hormone pulses by restriction of glucose availability is mediated by sensors in the brain stem. Endocrinology 1996: 137; 1171-1176.

Nakamura A, Osonoi T, and Terauchi Y. Relationship between urinary sodium excretion and pioglitazone-induced edema. J Diabetes Investig 2010: 1; 208-211.

Nattiv A, Loucks AB, Manore MM, Sanborn CF, Sundgot-Borgen J, and Warren MP. American College of Sports Medicine position stand. The female athlete triad. Med Sci Sports Exerc 2007: 39; 1867-1882. 
1305

1306

1307

1308

1309

1310

1311

1312

1313

1314

1315

1316

1317

1318

1319

1320

1321

1322

1323

1324

1325

1326

1327

1328

1329

1330

1331

1332

1333

1334

1335

1336

1337

1338

1339

1340

1341

1342

1343

1344

1345

1346

1347

1348

1349

1350

Navarro VM and Kaiser UB. Metabolic influences on neuroendocrine regulation of reproduction. Curr Opin Endocrinol Diabetes Obes 2013: 20; 335-341.

Neuberg M, Pawlosek W, Jakubowska-Szwed B, Waciega A, and Turkiewicz M. [Repeated amenorrhea in an adolescent girl in the course of flood disaster in Klodzko Region, July 1997]. Ginekol Pol 1999: 70; 378-382.

Olster DH and Ferin M. Corticotropin-releasing hormone inhibits gonadotropin secretion in the ovariectomized rhesus monkey. J Clin Endocrinol Metab 1987: 65; 262-267.

Palm-Fischbacher $\mathrm{S}$ and Ehlert U. Dispositional resilience as a moderator of the relationship between chronic stress and irregular menstrual cycle. J Psychosom Obstet Gynaecol 2014: 35; 42-50.

Pauli SA and Berga SL. Athletic amenorrhea: energy deficit or psychogenic challenge? Ann $N Y$ Acad Sci 2010: 1205; 33-38.

Pentz I and Nakic Rados S. Functional hypothalamic amenorrhea and its psychological correlates: a controlled comparison. J Reprod Infant Psychol 2017: 35; 137-149.

Peric M, Zenic N, Sekulic D, Kondric M, and Zaletel P. Disordered eating, amenorrhea, and substance use and misuse among professional ballet dancers: Preliminary analysis. Med Pr 2016: 67; 21-27.

Petraglia F, Sutton S, Vale W, and Plotsky P. Corticotropin-releasing factor decreases plasma luteinizing hormone levels in female rats by inhibiting gonadotropin-releasing hormone release into hypophysial-portal circulation. Endocrinology 1987: 120; 1083-1088.

Pirke KM, Schweiger U, Strowitzki T, Tuschl RJ, Laessle RG, Broocks A, Huber B, and Middendorf R. Dieting causes menstrual irregularities in normal weight young women through impairment of episodic luteinizing hormone secretion. Fertil Steril 1989: 51; 263-268.

Pitts S, Blood E, Divasta A, and Gordon CM. Percentage body fat by dual-energy X-ray absorptiometry is associated with menstrual recovery in adolescents with anorexia nervosa. J Adolesc Health 2014: 54; 739-741.

Plant TM. The neurobiological mechanism underlying hypothalamic GnRH pulse generation: the role of kisspeptin neurons in the arcuate nucleus. F1000Res 2019: 8.

Qiu X, Dowling AR, Marino JS, Faulkner LD, Bryant B, Bruning JC, Elias CF, and Hill JW. Delayed puberty but normal fertility in mice with selective deletion of insulin receptors from Kiss1 cells. Endocrinology 2013: 154; 1337-1348.

Quigley ME, Sheehan KL, Casper RF, and Yen SS. Evidence for increased dopaminergic and opioid activity in patients with hypothalamic hypogonadotropic amenorrhea. $J$ Clin Endocrinol Metab 1980: 50; 949-954.

Raftogianni A, Roth LC, Garcia-Gonzalez D, Bus T, Kuhne C, Monyer H, Spergel DJ, Deussing JM, and Grinevich V. Deciphering the Contributions of CRH Receptors in the Brain and Pituitary to Stress-Induced Inhibition of the Reproductive Axis. Front Mol Neurosci 2018: 11; 305.

Ralph CR, Lehman MN, Goodman RL, and Tilbrook AJ. Impact of psychosocial stress on gonadotrophins and sexual behaviour in females: role for cortisol? Reproduction 2016: 152; R1-r14.

Rani K, Tiwari SC, Singh U, Agrawal GG, and Srivastava N. Six-month trial of Yoga Nidra in menstrual disorder patients: Effects on somatoform symptoms. Industrial psychiatry journal 2011: 20; 97-102.

Rasky E, Stronegger WJ, and Freidl W. The relationship between body weight and patterns of smoking in women and men. Int J Epidemiol 1996: 25; 1208-1212. 
Reed JL, De Souza MJ, Mallinson RJ, Scheid JL, and Williams NI. Energy availability discriminates clinical menstrual status in exercising women. J Int Soc Sports Nutr 2015: 12; 11.

Remorgida V, Venturini PL, Anserini P, Salerno E, and De Cecco L. Naltrexone in functional hypothalamic amenorrhea and in the normal luteal phase. Obstet Gynecol 1990: 76; 1115-1120.

Rettberg JR, Yao J, and Brinton RD. Estrogen: a master regulator of bioenergetic systems in the brain and body. Front Neuroendocrinol 2014: 35; 8-30.

Richards JS, Ireland JJ, Rao MC, Bernath GA, Midgley AR, Jr., and Reichert LE, Jr. Ovarian follicular development in the rat: hormone receptor regulation by estradiol, follicle stimulating hormone and luteinizing hormone. Endocrinology 1976: 99; 1562-1570.

Rigaud D, Pennacchio H, Bizeul C, Reveillard V, and Verges B. Outcome in AN adult patients: a 13-year follow-up in 484 patients. Diabetes Metab 2011: 37; 305-311.

Roa J, Garcia-Galiano D, Castellano JM, Gaytan F, Pinilla L, and Tena-Sempere M. Metabolic control of puberty onset: new players, new mechanisms. Mol Cell Endocrinol 2010: 324; 87-94.

Roland AV and Moenter SM. Regulation of gonadotropin-releasing hormone neurons by glucose. Trends Endocrinol Metab 2011: 22; 443-449.

Ronnekleiv OK, Qiu J, and Kelly MJ. Arcuate Kisspeptin Neurons Coordinate Reproductive Activities with Metabolism. Semin Reprod Med 2019: 37; 131-140.

Roupas ND and Georgopoulos NA. Menstrual function in sports. Hormones (Athens) 2011: 10; 104-116.

Ruiz-Cortes ZT, Martel-Kennes Y, Gevry NY, Downey BR, Palin MF, and Murphy BD. Biphasic effects of leptin in porcine granulosa cells. Biol Reprod 2003: 68; 789-796.

Saketos M, Sharma N, and Santoro NF. Suppression of the hypothalamic-pituitary-ovarian axis in normal women by glucocorticoids. Biol Reprod 1993: 49; 1270-1276.

Sanborn CF, Martin BJ, and Wagner WW, Jr. Is athletic amenorrhea specific to runners? Am J Obstet Gynecol 1982: 143; 859-861.

Sanchez-Garrido MA and Tena-Sempere M. Metabolic control of puberty: roles of leptin and kisspeptins. Horm Behav 2013: 64; 187-194.

Sanders KA and Bruce NW. Psychosocial stress and the menstrual cycle. J Biosoc Sci 1999: 31; 393-402.

Sawyer CH. First Geoffrey Harris Memorial Lecture. Some Recent Developments in BrainPituitary-Ovarian Physiology. Neuroendocrinology 1975: 17; 97-124.

Schedlowski M, Wiechert D, Wagner TOF, and Tewes U. Acute psychological stress increases plasma levels of cortisol, prolactin and TSH. Life Sciences 1992: 50; 1201-1205.

Schliep KC, Zarek SM, Schisterman EF, Wactawski-Wende J, Trevisan M, Sjaarda LA, Perkins NJ, and Mumford SL. Alcohol intake, reproductive hormones, and menstrual cycle function: a prospective cohort study. Am J Clin Nutr 2015: 102; 933-942.

Schneider LF, Monaco SE, and Warren MP. Elevated ghrelin level in women of normal weight with amenorrhea is related to disordered eating. Fertil Steril 2008: 90; 121-128.

Shanan J, Brzezinski A, Sulman F, and Sharon M. Active coping behavior, anxiety, and cortical steroid excretion in the prediction of transient amenorrhea. Behav Sci 1965: 10; 461465.

Shen $\mathrm{ZQ}, \mathrm{Xu} J \mathrm{~J}$, and Lin JF. Resumption of menstruation and pituitary response to gonadotropinreleasing hormone in functional hypothalamic amenorrhea subjects undertaking estrogen replacement therapy. J Endocrinol Invest 2013: 36; 812-815. 
Shilaih M, Clerck V, Falco L, Kubler F, and Leeners B. Pulse Rate Measurement During Sleep Using Wearable Sensors, and its Correlation with the Menstrual Cycle Phases, A Prospective Observational Study. Sci Rep 2017: 7; 1294.

Smith AR, Ortiz SN, Forrest LN, Velkoff EA, and Dodd DR. Which Comes First? An Examination of Associations and Shared Risk Factors for Eating Disorders and Suicidality. Curr Psychiatry Rep 2018: 20; 77.

Sobrinho LG. Prolactin, psychological stress and environment in humans: adaptation and maladaptation. Pituitary 2003: 6; 35-39.

Somigliana E, Paffoni A, Busnelli A, Filippi F, Pagliardini L, Vigano P, and Vercellini P. Age-related infertility and unexplained infertility: an intricate clinical dilemma. Human Reproduction 2016: 31; 1390-1396.

Sominsky L, Hodgson DM, McLaughlin EA, Smith R, Wall HM, and Spencer SJ. Linking Stress and Infertility: A Novel Role for Ghrelin. Endocr Rev 2017: 38; 432-467.

Sonigo C, Bouilly J, Carre N, Tolle V, Caraty A, Tello J, Simony-Conesa FJ, Millar R, Young J, and Binart N. Hyperprolactinemia-induced ovarian acyclicity is reversed by kisspeptin administration. J Clin Invest 2012: 122; 3791-3795.

Sonino N, Navarrini C, Ruini C, Fallo F, Boscaro M, and Fava GA. Life events in the pathogenesis of hyperprolactinemia. Eur J Endocrinol 2004: 151; 61-65.

Sowinska-Przepiera E, Andrysiak-Mamos E, Jarzabek-Bielecka G, Walkowiak A, OsowiczKorolonek L, Syrenicz M, Kedzia W, and Syrenicz A. Functional hypothalamic amenorrhoea - diagnostic challenges, monitoring, and treatment. Endokrynol Pol 2015: 66; 252-260.

Sterling WM, Golden NH, Jacobson MS, Ornstein RM, and Hertz SM. Metabolic assessment of menstruating and nonmenstruating normal weight adolescents. Int J Eat Disord 2009: 42; 658-663.

Suh BY, Liu JH, Berga SL, Quigley ME, Laughlin GA, and Yen SS. Hypercortisolism in patients with functional hypothalamic-amenorrhea. J Clin Endocrinol Metab 1988: 66; 733-739.

Sun Y, Ahmed S, and Smith RG. Deletion of ghrelin impairs neither growth nor appetite. Mol Cell Biol 2003: 23; 7973-7981.

Sun Y, Butte NF, Garcia JM, and Smith RG. Characterization of adult ghrelin and ghrelin receptor knockout mice under positive and negative energy balance. Endocrinology 2008: 149; 843-850.

Swenne I. Weight requirements for return of menstruations in teenage girls with eating disorders, weight loss and secondary amenorrhoea. Acta Paediatr 2004: 93; 1449-1455.

Sydenham A. Amenorrhoea at Stanley Camp, Hong Kong, during internment. Br Med J 1946: 2; 159.

Szymanski LA, Schneider JE, Friedman MI, Ji H, Kurose Y, Blache D, Rao A, Dunshea FR, and Clarke IJ. Changes in insulin, glucose and ketone bodies, but not leptin or body fat content precede restoration of luteinising hormone secretion in ewes. $J$ Neuroendocrinol 2007: 19; 449-460.

Tena-Sempere M. Roles of ghrelin and leptin in the control of reproductive function. Neuroendocrinology 2007: 86; 229-241.

Tena-Sempere M. Interaction between energy homeostasis and reproduction: central effects of leptin and ghrelin on the reproductive axis. Horm Metab Res 2013: 45; 919-927.

Theorell T. Prolactin-a hormone that mirrors passiveness in crisis situations. Integrative Physiological and Behavioral Science 1992: 27; 32-38. 
Tinahones FJ, Martinez-Alfaro B, Gonzalo-Marin M, Garcia-Almeida JM, Garrido-Sanchez L, and Cardona F. Recovery of menstrual cycle after therapy for anorexia nervosa. Eat Weight Disord 2005: 10; e52-55.

Tokatly Latzer I, Kidron-Levy H, Stein D, Levy AE, Yosef G, Ziv-Baran T, and Dubnov-Raz G. Predicting Menstrual Recovery in Adolescents With Anorexia Nervosa Using Body Fat Percent Estimated by Bioimpedance Analysis. J Adolesc Health 2019: 64; 454-460.

Tolle V, Kadem M, Bluet-Pajot MT, Frere D, Foulon C, Bossu C, Dardennes R, Mounier C, Zizzari $P$, Lang $F$, et al. Balance in ghrelin and leptin plasma levels in anorexia nervosa patients and constitutionally thin women. J Clin Endocrinol Metab 2003: 88; 109-116.

Tschugguel W and Berga SL. Treatment of functional hypothalamic amenorrhea with hypnotherapy. Fertil Steril 2003: 80; 982-985.

Turzillo AM, Nolan TE, and Nett TM. Regulation of gonadotropin-releasing hormone (GnRH) receptor gene expression in sheep: interaction of $\mathrm{GnRH}$ and estradiol. Endocrinology 1998: 139; 4890-4894.

Vazquez MJ, Velasco I, and Tena-Sempere M. Novel mechanisms for the metabolic control of puberty: implications for pubertal alterations in early-onset obesity and malnutrition. $J$ Endocrinol 2019: 242; R51-r65.

Villanueva AL, Schlosser C, Hopper B, Liu JH, Hoffman DI, and Rebar RW. Increased cortisol production in women runners. J Clin Endocrinol Metab 1986: 63; 133-136.

von Elm E, Altman DG, Egger M, Pocock SJ, Gotzsche PC, and Vandenbroucke JP. The Strengthening the Reporting of Observational Studies in Epidemiology (STROBE) statement: guidelines for reporting observational studies. Lancet 2007: 370; 1453-1457.

Voorhuis M, Onland-Moret NC, van der Schouw YT, Fauser BC, and Broekmans FJ. Human studies on genetics of the age at natural menopause: a systematic review. Hum Reprod Update 2010: 16; 364-377.

Wade GN and Jones JE. Neuroendocrinology of nutritional infertility. Am J Physiol Regul Integr Comp Physiol 2004: 287; R1277-1296.

Wagenmaker ER, Breen KM, Oakley AE, Tilbrook AJ, and Karsch FJ. Psychosocial stress inhibits amplitude of gonadotropin-releasing hormone pulses independent of cortisol action on the type II glucocorticoid receptor. Endocrinology 2009: 150; 762-769.

Walf $A A$ and Frye CA. A review and update of mechanisms of estrogen in the hippocampus and amygdala for anxiety and depression behavior. Neuropsychopharmacology 2006: 31; 1097-1111.

Warren MP. The effects of exercise on pubertal progression and reproductive function in girls. J Clin Endocrinol Metab 1980: 51; 1150-1157.

Warren MP and Perlroth NE. The effects of intense exercise on the female reproductive system. J Endocrinol 2001: 170; 3-11.

Warren MP, Voussoughian F, Geer EB, Hyle EP, Adberg CL, and Ramos RH. Functional hypothalamic amenorrhea: hypoleptinemia and disordered eating. J Clin Endocrinol Metab 1999: 84; 873-877.

Watson TL and Andersen AE. A critical examination of the amenorrhea and weight criteria for diagnosing anorexia nervosa. Acta Psychiatr Scand 2003: 108; 175-182.

Weber RF and Calogero AE. Prolactin stimulates rat hypothalamic corticotropin-releasing hormone and pituitary adrenocorticotropin secretion in vitro. Neuroendocrinology 1991: 54; 248-253.

Weisberg E. Smoking and reproductive health. Clin Reprod Fertil 1985: 3; 175-186. 
Welt CK, Chan JL, Bullen J, Murphy R, Smith P, DePaoli AM, Karalis A, and Mantzoros CS. Recombinant human leptin in women with hypothalamic amenorrhea. $N$ Engl J Med 2004: 351; 987-997.

Wildt $L$ and Leyendecker $G$. Induction of ovulation by the chronic administration of naltrexone in hypothalamic amenorrhea. J Clin Endocrinol Metab 1987: 64; 1334-1335.

Wildt L, Leyendecker G, Sir-Petermann T, and Waibel-Treber S. Treatment with naltrexone in hypothalamic ovarian failure: induction of ovulation and pregnancy. Hum Reprod 1993: 8; 350-358.

William Tank A and Lee Wong D. Peripheral and Central Effects of Circulating Catecholamines. Comprehensive Physiology. 2014. pp 1-15.

Williams NI, Berga SL, and Cameron JL. Synergism between psychosocial and metabolic stressors: impact on reproductive function in cynomolgus monkeys. Am J Physiol Endocrinol Metab 2007: 293; E270-276.

Williams NI, Helmreich DL, Parfitt DB, Caston-Balderrama A, and Cameron JL. Evidence for a causal role of low energy availability in the induction of menstrual cycle disturbances during strenuous exercise training. J Clin Endocrinol Metab 2001: 86; 5184-5193.

Williams NI, Leidy HJ, Hill BR, Lieberman JL, Legro RS, and De Souza MJ. Magnitude of daily energy deficit predicts frequency but not severity of menstrual disturbances associated with exercise and caloric restriction. Am J Physiol Endocrinol Metab 2015: 308; E29-E39.

Winkler LA, Frolich JS, Schulpen M, and Stoving RK. Body composition and menstrual status in adults with a history of anorexia nervosa-at what fat percentage is the menstrual cycle restored? Int J Eat Disord 2017: 50; 370-377.

Wong SL, DePaoli AM, Lee JH, and Mantzoros CS. Leptin hormonal kinetics in the fed state: effects of adiposity, age, and gender on endogenous leptin production and clearance rates. J Clin Endocrinol Metab 2004: 89; 2672-2677.

Wu S, Divall S, Wondisford F, and Wolfe A. Reproductive tissues maintain insulin sensitivity in diet-induced obesity. Diabetes 2012: 61; 114-123.

Zuure WA, Roberts AL, Quennell JH, and Anderson GM. Leptin signaling in GABA neurons, but not glutamate neurons, is required for reproductive function. J Neurosci 2013: 33; 17874-17883. 